\title{
A Portrait of Entrants and Exits
}

\author{
by \\ John R. Baldwin \\ No. 121 \\ 11F0019MPE No. 121 \\ ISSN: $1200-5223$ \\ ISBN: 0-660-17734-X \\ Micro-Economic Analysis Division \\ 24-B R.H. Coats Building \\ Ottawa, K1A 0T6 \\ Statistics Canada \\ (613) 951-8588 \\ Facsimile Number: (613) 951-5403 \\ Email: baldjoh@statcan.ca
}

\section{June 1999}

This paper was written for a conference on small firms, organized by the Small Business Administration, held in Washington, D.C., 1997. A reduced version will appear in "Are Small Firms Important? Their Role and Impact”, edited by Zoltan Acs. Kluwer: May 1999.

This paper represents the views of the author and does not necessarily reflect the opinions of Statistics Canada. 


\section{Table of Contents}

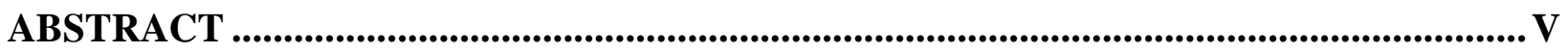

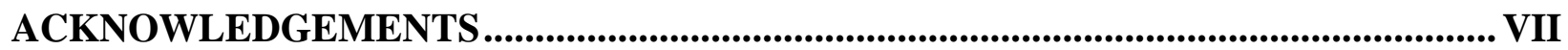

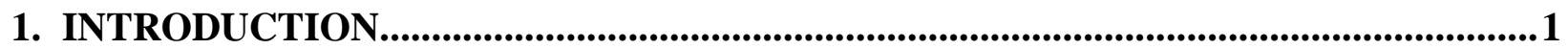

2. THE SIZE OF ENTRY AND EXIT ..................................................................................2

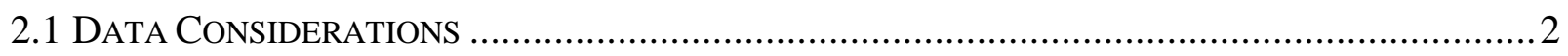

2.2 THE EVIDENCE FOR THE MANUfACTURING SECTOR.......................................................

2.3 A COMPARISON OF ENTRY AND EXIT IN THE GoOdS AND SERVICE SECTORS ........................5

3. PRODUCTIVITY AND ENTRANTS ..................................................................................

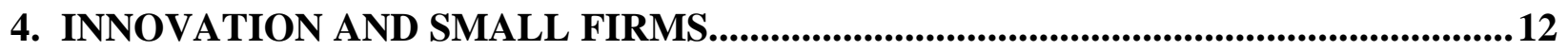

5. ENTRANTS AND INNOVATION...................................................................................19

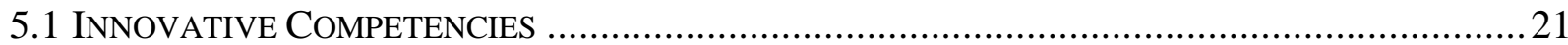

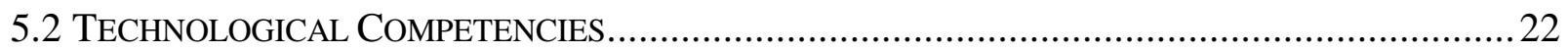

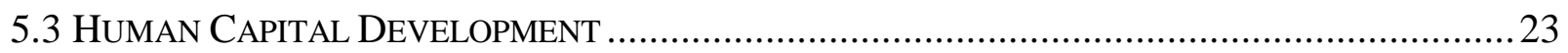

5.4 COMPREHENSIVENESS OF INNOVATION IN THE ENTRANT POPULATION …………................24

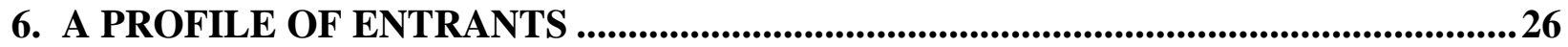

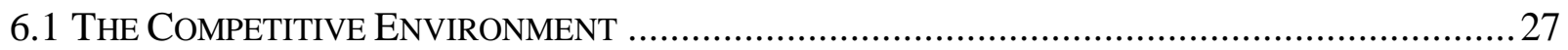

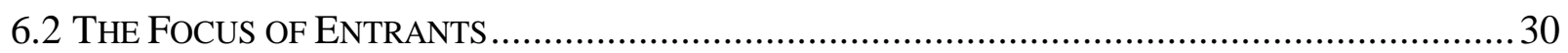

6.3 GROWTH OF ENTRANTS AND THE IMPORTANCE OF INNOVATION ....................................... 32

6.4 INNOVATION AND COMPLEMENTARY COMPETENCIES ....................................................... 37

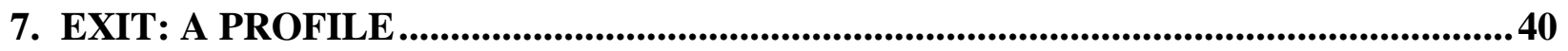

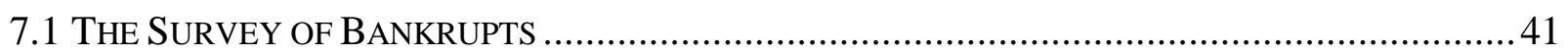

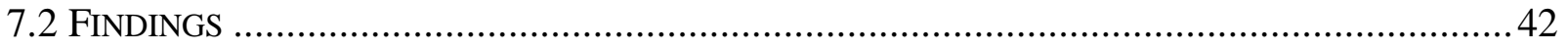

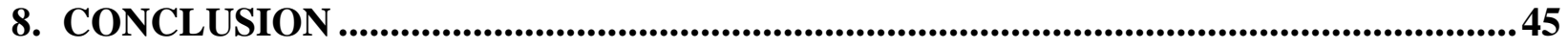

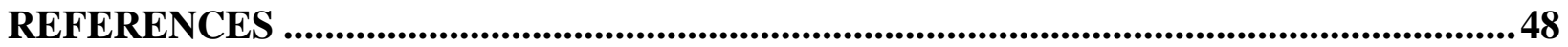

Analytical Studies Branch - Research Paper Series $\quad$ - iii - $\quad$ Statistics Canada No. 11F0019MPE No. 



\begin{abstract}
Entry and exit are important phenomena. This paper reviews the evidence on the size of this process and its contribution to productivity and innovation. It then develops a detailed portrait of the characteristics of new firms that survive and those that fail. In doing so, it examines the type of competencies that are developed in both groups of firms. It asks which competencies are developed by new firms. In particular, it focuses on the innovative capabilities of new firms. It shows that small firms in general and entrants in particular are heterogeneous when it comes to their innovative activity. The types of innovative activity in which they are engaged vary widely. Some focus on R\&D and new products. Others focus on new technologies. Still others stress the development of human capital. In addition, this paper examines the competitive environment that new firms face and the connection between growth and innovation. It also examines the complementary skills that are employed by innovators. Finally, the paper focuses on the causes of failure in the firm population. It extends earlier work that finds that failing firms differ from surviving firms in terms of basic competencies-management, financial management and marketing capabilities.
\end{abstract}

Keywords: entry, exit, innovation 



\section{Acknowledgements}

I am indebted to a number of individuals for their co-authorship on material described hereinPaul Gorecki with whom I investigated entry, Mohamed Rafiquzzaman with whom I worked on longitudinal files and the bankruptcy survey, and Joanne Johnson who assisted me with the entry survey. None are responsible for the interpretations contained herein. 



\section{Introduction}

Recent studies have demonstrated the extent of dynamic change that the industrial population undergoes. ${ }^{1}$ Competition constantly leads some firms to grow and others to decline. The amount of market share transferred in a typical industry over a decade ranges between $30 \%$ and $40 \%$. An important part of this turnover comes from the entry and exit of firms.

Each year large numbers of entrepreneurs start new firms. In most years, entrants that are one year old account for between $15 \%$ and $20 \%$ of the firm population in the commercial sector. For the majority of these firms, life is short. Most new entrants exit shortly after birth. About 1 in 5 new firms survive to their tenth birthday.

Experimentation associated with entry and exit is the key to a dynamic market-based economy. New entrepreneurs constantly offer consumers new products-both in terms of the basic good and the level of service that accompanies it. Many of these new firms will fail. These failures involve a cost - both in human and financial terms. But these resources should not be regarded as wasted-anymore than resources that are expended on obtaining information in a world of imperfect information are wasted. Failures are an investment that society makes in the dynamic competitive process.

New firms provide an important stimulus to the industrial population. A few small entrants grow to become the new dynamos of the industrial system. Others remain relatively small but provide an important source of innovation in the small-firm sector-especially when it comes to quality differentiation. Smaller firms excel in their ability to provide quality and flexibility of service (Baldwin et al., 1994). Small firms are constantly changing their product offerings-with respect to both types of products and services offered. Small firms are adept at ascertaining changing consumer tastes with regards to the amount of services that are bundled with a product, or being flexible with regards to other aspects of the product offering. New small firms that are better able to sense consumer requirements are constantly replacing other small firms that are less able to do so (Baldwin, 1995). One manifestation of the success of small entrants is their tendency to pay higher wages and to be more productive than those firms that they force out of the market (Baldwin, 1995; 1996). It is the process of entry and exit that generates information on which combinations of products and services best satisfy consumer tastes.

The benefits from entry and exit are, therefore, large — but so too are the costs. Unfortunately, the costs are all too visible while the benefits are much more difficult to measure empirically. It is the turnover from entry and exit that rewards innovative activity and contributes to productivity growth. This dynamic change in the industrial population stems from different capabilities in firms. To understand how these capabilities contribute to growth and decline, it is necessary to study entrants and exits and relate their performance to differences in strategies and pursued activities. This paper summarizes the information that we have on the strategies being pursued by both groups. It also examines the reasons that some entrants survive and others fail.

\footnotetext{
${ }^{1}$ See Baldwin (1995). The Dynamics of Industrial Competition.
} 


\section{The Size of Entry and Exit}

Entry is at the heart of two quite disparate economic paradigms. On the one hand are depictions of the entrepreneur as the key building block in the economic system (Knight, 1921; Kirzner, 1972). On the other hand is the traditional neo-classical approach that portrays entry and exit as one of the equilibrating forces that drive above-normal profits in an industry down and that equates price and average cost in an industry. ${ }^{2}$ Since entry plays such a prominent role for both groups, we will examine three quantitative pieces of evidence to see if they support the notion that entry is important. In this section, we investigate whether the size of entry and exit warrants the attention that it has received.

\subsection{Data Considerations}

Empirical studies of the entry process were restricted primarily to case studies (i.e., Mansfield, 1962) until the advent of large micro-databases, most of which emanate from statistical agencies that computerized their files on firm populations during the 1970s and 1980s. These databases originate from official statistical agency files often derived from the manufacturing population (the LRD at the U.S. Bureau of the Census), or from private sector sources such as the longitudinal file that was developed at the Small Business Administration from Dun and Bradstreet records. Similar files exist in other countries. For example, Canadian files have been derived from data on manufacturing firms that were collected by the Census of Manufactures (see Baldwin, 1995) and a more extensive file on the population of all firms derived from tax records (see Baldwin, Dupuy and Penner, 1992). Other countries have developed files-often from administrative sources such as social security records (OECD, 1996).

These databases are not perfect and all too often have been accepted without careful examination of the flaws inherent in them. The Dun and Bradstreet records have received the closest public scrutiny. ${ }^{3}$ Two problems are noteworthy. First, coverage of populations has been an issue. Second, the meaning or validity of the entrant category that is measured is an issue that all too often goes unresolved.

Entry is measured as the appearance in these files of a new firm. Firms are records in a file. Entry then is whatever event causes the creators of these files to decide that a firm submitting data deserves a new record number-or the data for the entity would be assigned to a firm that in some previous period already existed. Unfortunately, many files were not originally established with clear rules as to when old record-identifiers would be terminated and new record-identifiers birthed. In some files, firms were arbitrarily assigned new record numbers over time and an ongoing entity falsely appears to die and then be born. This often arises when a merger or a change in control occurs. When this occurs, the number of births and deaths is overestimated.

\footnotetext{
${ }^{2}$ For a number of empirical studies that adopt this approach, see Geroski and Schwalbach (1991).

${ }^{3}$ See Baldwin and Gorecki (1990, ch. 5 ), Davis, Haltiwanger and Schuh (1996, pp. 70-72) for a discussion of the shortcomings of the D\&B files.
} 
Two solutions are available. First, detailed estimates of the error rates can be derived by sampling the database and investigating the error rate. ${ }^{4}$ Second, outside information can be used to correct the database. For example, the Canadian longitudinal file derived from tax records tracked workers over time to correct for false births and deaths (Baldwin, Dupuy and Penner, 1992).

There is also a question about the coverage of a database. New firms go through several stages. They may just be an idea in an entrepreneur's mind, or a tentative experiment that may consist only of the founder working in his garage or home office. Usually at a later stage, they begin to hire employees. At a still later stage, they are incorporated into official business registers and surveyed either by a statistical agency or by a credit rating agency. It is clear from this taxonomy that there is no 'correct' time at which entry should be measured. Most databases capture firms at an arbitrary point in their birthing experience.

What then are annual rates like? This will depend upon the database used, whether the rates are calculated using number of firms or the percentage of employment that is accounted for by entrants, whether we look at the short-run, and on which sector is chosen. Databases differ in the cut-off used, with some catching the arrival of new firms earlier than others. The ones that capture new firms earliest report the highest entry and exit rates. This is because the very earliest firms to enter an industry have a much higher exit rate. But these firms are also very small and their omission from a database will have very little impact upon entry rates calculated using employment or shipments. 5

The intensity of entry varies across sectors. Because of this, the aggregate rate of entry will differ depending whether the rates are calculated using a weighted or unweighted average - that is, if all industries are taken together (the sum of all entrants over the sum of all firms) or if the entry rate is calculated for each industry individually and then averaged. Typically, employment entry rates are lower for all of manufacturing than if calculated at the industry level and then averagedbecause the sectors with the largest employment tend to have the lowest entry rates.

Entry rates can also be calculated over short (i.e., one year) or over longer periods of time (i.e., five years). The latter rate, when annualized, will generally be lower than the former because it winnows out those entrants who fail sometime during the first four years. On the other hand, rates calculated over a longer period give a better picture of those entrants who are more permanent.

Finally, entry rates are larger when calculated using the number of new firms that enter an industry than when a measure of size is used-such as the employment in entrants as a percentage of total employment. This occurs because entrants are smaller than the average firm.

\footnotetext{
${ }^{4}$ See Baldwin (1995) for the work done on the Canadian manufacturing database to estimate the error rate.

${ }^{5}$ See Baldwin and Gorecki (1990) for a discussion of this point.
} 


\subsection{The Evidence for the Manufacturing Sector}

Because of the considerations outlined above, estimates of the size of entry that emerge from different sources cannot be easily compared. Nevertheless, there is one carefully constructed set of comparisons that have been done for Canada and the U.S., using data that have been collected in a similar manner using similar definitions (Baldwin, Dunne and Haltiwanger, 1998). We make use of these data to provide an overview of the quantitative importance of entry in the United States and Canada, show that it is quite similar, and then proceed to use some specially constructed Canadian databases to investigate issues relating to innovation and growth.

Strong similarities in the entry process in Canada and the United States occur when they are compared directly over similar time periods, with similar levels of aggregation, and with similar definitions of populations. ${ }^{6}$ Short-run annual entry rates to the manufacturing sector in aggregate are quite similar when employment entry rates are calculated. The annual entry rates to manufacturing as a whole from 1972 to 1986 for select years where data was available for both countries averaged about 2.4\% for Canada and 1.9\% for the United States (Baldwin, 1995, p. 127). When calculated over five year periods (1972-77, and 1977-82), the Canadian average across two-digit industries was 10.9\% while the US average was 11.3\% (Baldwin, 1995, p. 137). It is also important to note that, in both countries, the death rates were quite similar to the birth rates.

These rates need to be set in context. Entry is not the only process that leads to the turnover of the firm population. Growth and decline in the incumbent population is also occurring. At any point in time, the population can be divided into those that grow and those that decline. Job turnover is the sum of all employment increases in those growing (job growth) and the sum of the change in employment in those declining (job loss). The importance of entry and exit can be calculated as the share of job growth that is accounted for by entry, or the share of job decline that is accounted for by exit. When this is done using comparable manufacturing databases for Canada and the United States, the results are quite similar. For year to year changes from 1970 to 1985, job creation due to entry in Canada averaged 27\% of the total job increase; in the United States, it averaged 21\% (Baldwin, 1995, p. 126). Calculated over two comparable five-year periods (1972-77, 1977-82), entry accounted for $45 \%$ of job growth in Canada and $44 \%$ in the United States. As the length of period over which the importance of entry is calculated, entry becomes relatively more important.

One way to judge the numerical importance of new firms is to examine the extent to which the population is made up of recent entrants-firms that have entered in the recent past. If all entrants disappeared almost instantaneously, then the importance of firms that have entered today should not differ substantially from the short-run rates quoted above. This is not the case. Canadian data calculated across all industries and then averaged are available for a long time period -10 and 20 years-that show how this process continues to accumulate. On average, over $39 \%$ of all plants in existence in the average Canadian manufacturing 4-digit industry in 1980 belonged to firms that

\footnotetext{
${ }^{6}$ See Baldwin (1995, ch. 6).
} 
had entered since 1970; these plants accounted for about 16\% of shipments (Baldwin, 1995, p. 409). Ten years later in 1990 , over $61 \%$ of all plants in existence belonged to firms that had entered since 1970; these plants accounted for about $34 \%$ of shipments. Entry is the force that brings brand new plants and firms into an industry. It results in a substantial change in the participants in an industry.

\subsection{A Comparison of Entry and Exit in the Goods and Service Sectors}

The majority of entry and exit studies have used data from the manufacturing sector. Here we use a database that covers both the goods and service sectors to examine the nature of the differences between the two. This database registers firms as soon as they hire their first employee. ${ }^{7}$ It is, therefore, even more current than the manufacturing database used above to compare Canada and the United States and it can be used to examine the entry and exit process in the goods and service sectors. ${ }^{8}$ For this section, we make use of a sample of all entrants who are born in the years 1984, 85 and 86 and who are less than 200 employees in 1994.

The contribution of new firms is determined by the rate at which they enter an industry, their rate of survival and the rate at which the survivors grow. Many firms are born each year. A large number of these die. But a sufficient number of these new firms achieve enough growth that the group of survivors as a whole makes an important contribution to employment at any one point in time-especially when groups of entrants in successive years are considered. The nature of the process, however, differs across the goods and the service sectors.

Over the 1984-86 period, new firms in any one year accounted for $18.9 \%$ of the population of businesses (Table 1, column 1). Entry is higher in the service sector (19.1\%) than in the goods producing sector $(14.3 \%)^{9}$

The importance of entrants differs considerably by size class. The smallest size class (0-9 employees) has the largest proportion of firms that have just entered; on average, $20.6 \%$ of firms in this class were born in the years 1984-86. Entry rates are lowest for the largest size class $(5.4 \%)$. Service industries have higher entry rates than do goods industries in the smallest two size classes-but not in the largest size class.

The importance of entry is somewhat less when calculated using employment size, since entrants are smaller than the average firm. If we calculate the rate of entry using employment in their first reporting year, employment in entrants is $5.8 \%$ (Table 1, column 3 ). If we recognize that entrants in their first reporting year may be reporting for only part of the year and take their second-year size for the entry rate calculation, the overall employment entry rate increases slightly to $6.7 \%$ (Table 1, column 4). The differences are much more substantial for the goods than the service

\footnotetext{
${ }^{7}$ For a description of this database, see Picot, Baldwin and Dupuy (1994).

${ }^{8}$ While ingenious efforts have been used to reduce the problem of false births in this database (Baldwin, Dupuy and Penner, 1992), it has not been completely eliminated.

${ }^{9}$ For this exercise, construction has been included in the service sector. The entry rate is calculated as the sum of all entrants over the years 1984-86 in the commercial sector.
} 
sector. In the former, they increase from $3.8 \%$ to $6 \%$, whereas they increase only from $6.3 \%$ to $7.2 \%$ for the services sector. Entrants to the goods sector then grow substantially in their first year-probably because they are more likely to be of a sub-optimal size than are entrants to the service sectors and they have to grow in order to survive. ${ }^{10}$

Table 1. Entry Rates-1984-86 Cohorts

\begin{tabular}{|c|c|c|c|c|c|c|c|}
\hline Industry & Size Class & $\begin{array}{c}\text { Entry } \\
\text { Rate-\% } \\
\text { of Firms }\end{array}$ & $\begin{array}{l}\text { Survival } \\
\text { Rate-\% } \\
\text { of Firms }\end{array}$ & $\begin{array}{c}\text { Entry } \\
\text { Rate-\% of } \\
\text { Employment } \\
\text { Year of Birth } \\
4 \\
\end{array}$ & \begin{tabular}{|c|} 
Entry \\
Rate- $\%$ \\
Employment \\
Using Year 2 \\
Size \\
5 \\
\end{tabular} & $\begin{array}{c}\text { Survival } \\
\text { Rate-\% of } \\
\text { Employment } \\
\text { Initial Year } \\
6 \\
\end{array}$ & $\begin{array}{c}\text { Survival } \\
\text { Entry } \\
\text { Rate Using } \\
1994 \\
\text { Employment } \\
7 \\
\end{array}$ \\
\hline \multirow[t]{4}{*}{ All } & 0 to 9 & 20.6 & 3.9 & 10.4 & 9.2 & 2.1 & 6.9 \\
\hline & 10 to 24 & 6.9 & 2.6 & 3.5 & 6.2 & 1.6 & 4.3 \\
\hline & 25 to 200 & 5.4 & 2.8 & 3.2 & 4.9 & 1.8 & 3.7 \\
\hline & Total & 18.9 & 3.8 & 5.8 & 6.7 & 1.9 & 4.9 \\
\hline \multirow[t]{4}{*}{ Goods } & 0 to 9 & 15.9 & 3.8 & 8.2 & 8 & 2.2 & 8.5 \\
\hline & 10 to 24 & 6 & 3 & 2.9 & 5.1 & 1.4 & 5.2 \\
\hline & 25 to 200 & 4.1 & 2.2 & 2.5 & 3.7 & 1.5 & 3 \\
\hline & Total & 14.3 & 3.7 & 3.8 & 6 & 1.7 & 4.7 \\
\hline \multirow[t]{4}{*}{ Service } & 0 to 9 & 21.6 & 3.9 & 10.8 & 9.5 & 2.1 & 6.6 \\
\hline & 10 to 24 & 6.8 & 2.5 & 3.6 & 6.4 & 1.7 & 4 \\
\hline & 25 to 200 & 3.9 & 3.1 & 3.5 & 5.4 & 2 & 4 \\
\hline & Total & 19.1 & 3.8 & 6.3 & 7.2 & 2 & 5 \\
\hline
\end{tabular}

Life for new firms is difficult. Many do not have the skills to survive. Four years after birth, only $50 \%$ of firms in the goods sector remain alive (Figure 1). At eight years, the survivors in the goods sector have fallen to $30 \%$ of the original number of entrants. The failure rate for firms in the service sector is even higher than for goods-producing firms. Over the first five years of life, the percentage of service firms surviving is at least 10 percentage points less than for goods firms. Over half of service entrants are dead before their third birthday, less than $21 \%$ survive to age eight.

Those firms who start smaller are particularly susceptible to failure. The survival rate is lowest (19\%) for entrants that started with fewer than nine employees. It is $52 \%$ for firms with more than 24 employees.

If entry is calculated not as the proportion of firms that are new each year (the instantaneous entry rate), but as the proportion that last until to 1994, (the survivor entry rate), the rate of entry is much smaller. For example, some $19 \%$ of firms are new each year (Table 1, column 2), but only $4 \%$ of the population are new firms who will survive past early childhood until their teen years (Table 1, column 3). While entrants account for about $6 \%$ of employment each year (Table 1 , column 4), only $2 \%$ of jobs initially are in those firms who will survive to their teen years (Table 1, column 6).

\footnotetext{
${ }^{10}$ See Audretsch (1995), Pakes and Erickson (1988).
} 
Figure 1

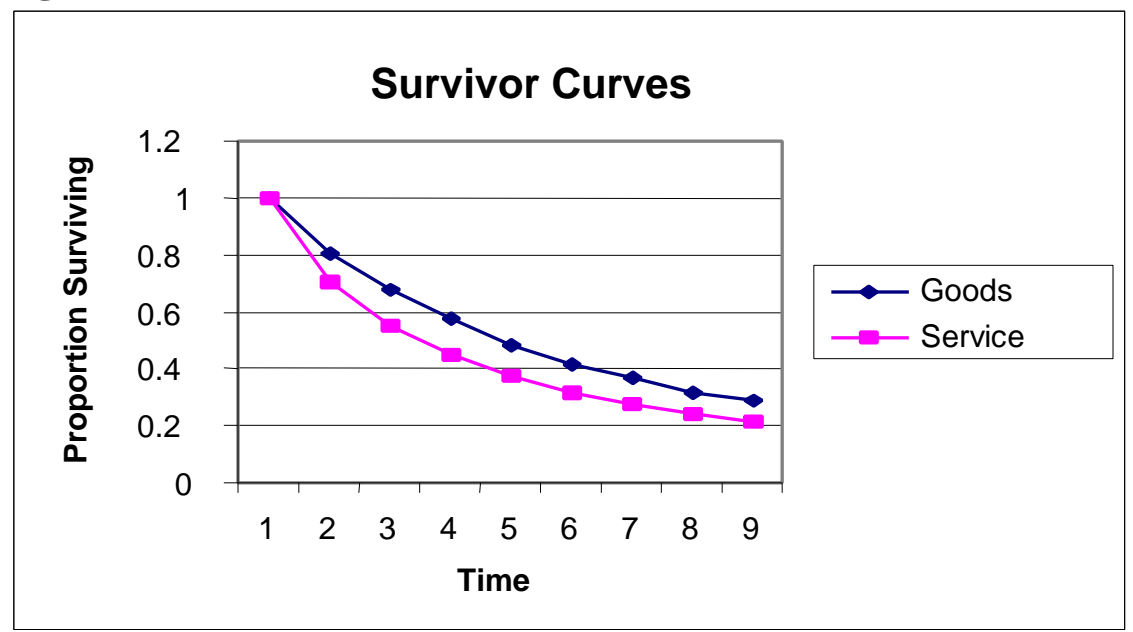

The instantaneous entry rates are higher in the service industries than the goods industries, both in terms of number of entrants and employment. In that sense, the service sector is subject to greater volatility from new competition. In contrast, while goods industries are harder to enter than service industries, entrants are better able to survive the vicissitudes of early childhood in goods than in service industries. These two tendencies offset one another so that the net effect is essentially zero: there are few differences in the survivor entry rates in the goods sector $(3.7 \%)$ and service sectors $(3.8 \%)$. Entry is a phenomenon with about equal importance if the group that are unsuccessful and exit are removed from the calculations (Figure 2). This means that, for each successful entrant, there is more experimentation in the service than the goods sector.

Figure 2

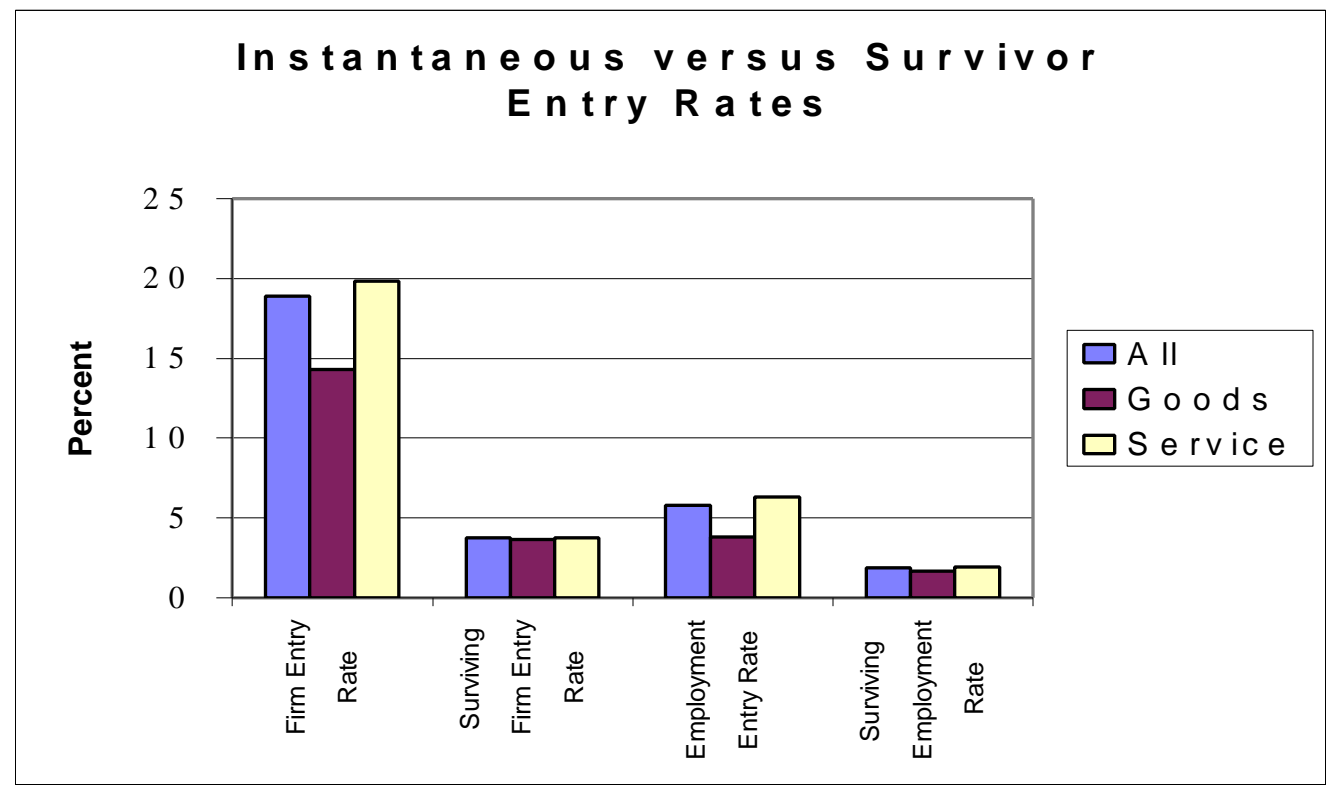


While a large percentage of new firms die, the remainder grow. The relative importance of a group or cohort of entrants depends upon whether the growth in the survivors offsets the demise in the overall number of firms in each cohort. The ultimate importance of an entry cohort can be determined by calculating their employment at a later stage in life and comparing it to total employment in all entrant firms in their year of birth. When this is done, the size of the survivors is impressive. Initially, the group of entrants accounted for $5.8 \%$ of employment (Table 1, column 4). Only $1.9 \%$ of employment is in entrants firms that will survive to their early teen years-but the employment of those who do survive will equal $4.9 \%$ of initial year employment (Table 1, columns 6 and 7, respectively). Thus, while those that survive make up a small proportion of those who enter, their growth is almost enough to maintain the importance of the cohort.

To set the performance of the survivors in context, we compare the total number of jobs created by all entrants in the year of birth, the number of jobs in the survivors in their birth year and finally the number of jobs in survivors in 1994 for the 1984, 1985 and 1986 entry cohorts (Figure 3). Growth in the goods industry is so robust that surviving entrants manage to increase the number of jobs in the cohort in 1994 above those in the birth year-despite the exit of new firms. ${ }^{11}$ In the service sector, growth is not sufficient to offset the exit of some of the cohort in their early infancy and the total employment in the entry cohort declines. What is significant is that an entry cohort's effect in the goods sector wears off less quickly than in the service sector, because survivors grow more rapidly. ${ }^{12}$

\section{Figure 3}

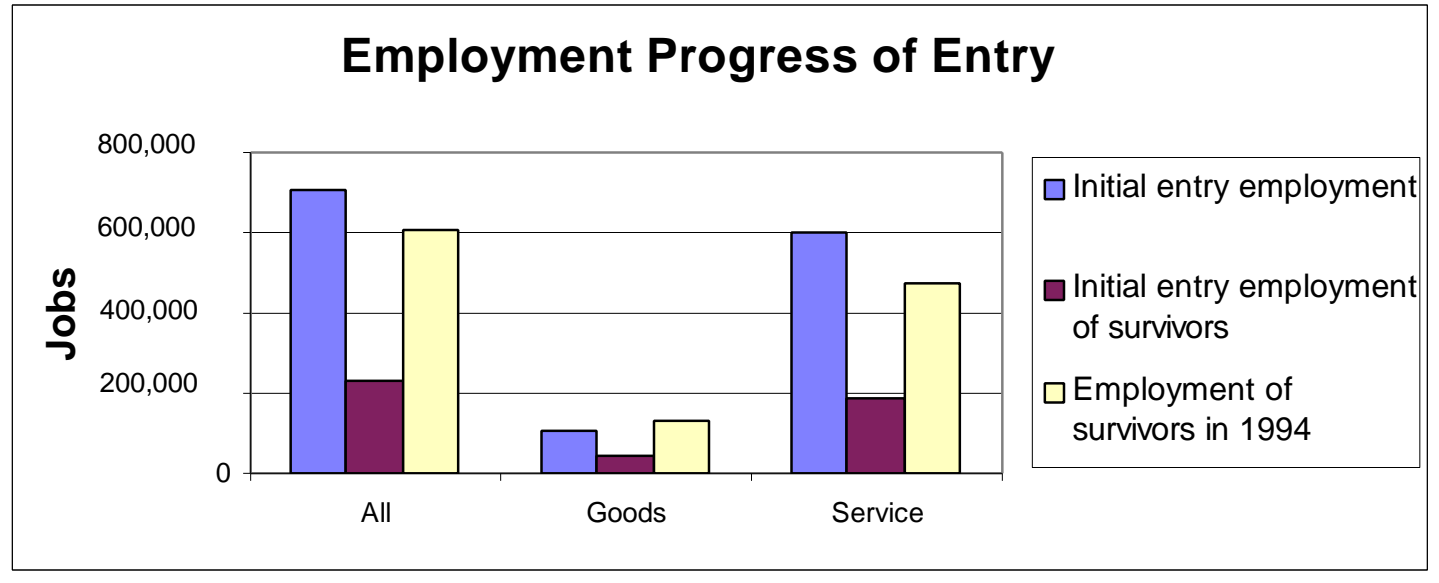

In summary, new entrants that have just arrived in any one year account for an impressive proportion of Canadian firms and jobs. On average, over the 1984 to 1986 period, approximately $19 \%$ of firms in operation had just commenced business that year. New firms, due to their small size and lack of experience face particularly difficult challenges, and only one in five survive a decade of operation. Many of those that do survive, however, grow considerably.

\footnotetext{
${ }^{11}$ See Baldwin (1996) for an examination of how this changes over different periods.

12 If we define the entrants' size as their employment in the first full year after birth, the employment of the goods cohort declines slightly but the effect of entrants in the goods sector still wears off less quickly in the goods than the service sector.
} 
Of course, much like the analysis presented in the previous section, considering the joint effect of several years of recent entrants magnifies the importance of the population of firms that have recently entered. The data that have been presented here suggest that in a steady state, somewhere between $70 \%$ and $80 \%$ of all firms in the goods and service sectors have been born in the last eight years. In 1995, some 74\% of the firms in existence had been born since 1984 and these firms accounted for $30 \%$ of all jobs.

\section{Productivity and Entrants}

The sheer size of the amount of entry and exit that is taking place is a testament to its importance. Competition is intense when the identity of the players change. Despite this, it is important to have supportive evidence of a concrete effect of turnover on the performance of an industry.

One such impact that might be expected is on productivity growth. New firms experiment with new ideas and processes. Their arrival should have a beneficial effect on productivity. Geroski (1991) tries to relate technical progress, efficiency and productivity growth at the industry level to entry rates and finds that roughly $30 \%$ of productivity growth could be related to entry. But this approach is somewhat of a 'black-box', using as it does aggregrate industry productivity measures and entry rates. It cannot explore the process that may be driving productivity at the micro-level and misses important detail. The link between productivity growth and entry requires a more detailed examination of data at the plant and firm level.

Even when this is done, the evidence on the effect of turnover on productivity is mixed. Some authors who have studied this phenomenon report that the contribution of entrants is relatively small (Hazledine, 1985; Bailey, Hulten and Campbell, 1992; Griliches and Regev, 1995). On the other hand, Baldwin (1995) and Haltiwanger (1998) find that entry of new firms makes a substantial contribution to productivity growth.

While some differences across countries in the measurement of the importance of entry and exit for productivity growth may come from disparities in databases, the differences that exist in the estimates of the effect of entry and exit on productivity stem more from conceptual differences about how entry affects productivity. These differences are the result of alternative ways of viewing the entry and exit process and the dynamics of competition.

Entry is part of a dynamic process that renews the industrial population. In order to measure its effects, we need to understand how the creation of new firms affects other firms-before we can establish the appropriate way to evaluate the effect of entrants on productivity.

Entry will affect productivity of other firms in one of two ways-one directly, the other indirectly. First, new firms replace other firms and, therefore, reduce the market share of competitors. Productivity in an industry is simply a weighted average of individual plant productivity-where for a measure like labour productivity, the weights are the employment shares of each firm. Any increase in the share of one firm changes the industry productivity if that firm's productivity 
differs from the average. An entrant, therefore, affects labour productivity if it displaces a firm with lower productivity. Second, entrants can affect the productivity level of other firms through demonstration effects. A new firm with a new technology may affect the productivity level in its industry if the new technology diffuses to other industry participants.

There is no doubt that firm turnover that arises because some firms grow and others decline serves to enhance productivity growth. When incumbent firms are examined, those that grow improve their productivity relative to those that decline. For example, Baldwin (1995) reports that there is little difference at the beginning of a period between those that are to gain and those that are to lose market share-but a decade later the growers have become more than $30 \%$ more productive than those losing share. ${ }^{13}$ The competitive process that shifts share from the losers to the gainers increases average productivity.

The effect of employment share turnover on productivity can be investigated by decomposing the algebraic expression for productivity growth over any period into three terms. ${ }^{14}$

\section{They are:}

1) the employment share of firms that are growing multiplied by change in productivity

2) the employment share of firms that are declining multiplied by change in productivity

3) the employment share that is transferred from losers to gainers multiplied by the productivity difference between gainers and losers.

The latter (expression \#3) can be used to calculate the effect of share turnover. When this is done for the manufacturing sector in Canada during the 1970s, it accounts for about $40 \%$ of total productivity growth in the continuing sector. But this component should not necessarily be equated to the productivity growth associated with the competitive process that caused some firms to grow at the expense of others. The competitive process is one where firms compete to produce better products and processes. The ones that are successful increase their productivity relative to others and take market share away from the losers. This process results both in productivity gains in the firms that gain share (term 1) and in the shifting of share from losers to gainers (term 3). Only the second term reflects, in some sense, the disembodied technical progress that is bestowed on those that are the least fortunate. ${ }^{15}$

In order to determine the effects of this competitive process, a counterfactual needs to be assumed. That is, we need to specify what would have happened in the absence of competition. One reasonable assumption is that without the competitive process, gaining firms would have had no greater productivity increase than losing firms and no employment share would have changed hands. In this case, the effect of competition is calculated as the sum of both the first and the third term. In Canada, this would account for some $80 \%$ of the total gain productivity in the continuing

\footnotetext{
${ }^{13}$ This is done using labour productivity for manufacturing establishments.

${ }^{14}$ See Baldwin (1995, ch. 9) for a more detailed discussion.

${ }^{15}$ Even part of this may be the result of spillovers from the incumbents who are more successful.
} 
sector. Very little of the total gain comes simply from exogenous technical change that is bestowed on firms losing market share. ${ }^{16}$

Research done for the U.S. also finds that turnover accounts for a substantial proportion of total productivity growth in the manufacturing sector. Baily, Hulten and Campbell (1992) report that about half of productivity growth comes from incumbent firm turnover. Haltiwanger (1998) reports some $38 \%$ comes from this source.

While it is a relatively straightforward exercise to understand how to calculate the changes in productivity that are associated with growth and decline in the incumbent population, it has turned out to be more difficult to reach agreement on the benefits associated with entry. One the reasons for this is a simple measurement issue; the other is the conceptual issue outlined above.

The conceptual issue revolves around the assumption that needs to be made about the way in which entry affects industry productivity. There are two questions that need to be answered before the appropriate measure can be agreed upon. First, from whom do entrants take away market share? Hazledine (1985) assumed that entrants take away market share from the average incumbent who is more productive than the average entrant. Not surprisingly, in this situation, he concluded that entry had a deleterious effect on overall productivity.

As a general rule, his assumption is inappropriate. Small new firms are not likely to replace larger firms in most situations. New firms are smaller than the average incumbents, they pay lower wages, they are less productive (Baldwin and Rafiquzzaman, 1996). Competition takes place within subgroups of an industry (Neuman, 1978). Small firms are more likely to compete against small firms. In doing so, entrants are most likely to displace exits. The evidence supporting this view is that the rate of entry and exit is closely related across industries (Cable and Schwalbach, 1991). Baldwin and Gorecki (1991) more carefully examine this proposition and find that, while entrants occasionally take share away from some incumbents who are even less productive than entrants, this is rare.

Establishing which group of firms is affected by entry is only part of the puzzle that must be solved before the effect of entry on productivity can be measured with micro-data. It is also necessary to estimate what would have happened to the productivity of the firms affected by entry in the absence of entry. Most estimates of the effect of entry essentially include only the third term above - the displaced share effect. As we pointed out, this involves making a strong assumption about what would have occurred to the productivity of those losing market share (the exits) in the absence of competition from those who succeeded in gaining share (the entrants). Those who use only the third term to measure the effect of entry are essentially assuming that in the absence of entry, the productivity levels of those who are removed from the market would have been equal to the new entrants - that exits would have done just as well as entrants in terms of productivity growth. Yet there is empirical evidence that this does not occur in the incumbent sector. Moreover, it seems unlikely that those who fail would have made the same progress as did entrants, since entry removes the less efficient firms from an industry.

${ }^{16}$ This can be thought of as the exogenous technical change that even the least competent enjoy. 
When the total effects of entry are measured taking into account both the displacement effect and the growth effect, entry is seen to have a significant impact (Baldwin, 1995, p. 234). Somewhere between $20 \%$ and $25 \%$ of productivity growth in a manufacturing industry in the 1970 s came from entry and exit. Haltiwanger (1998) reports the U.S. share as $18 \%$. It is true, however, that most of this gain comes from the productivity enhancing effect, not a market share displacement effect-because the share of entrants tends to be almost the same as the share of exits and therefore the displacement effect is small.

In conclusion, firms differ substantially in size. In the largest size groups, increases in average productivity come from a process that sees the successful incumbent firms displacing others. In the smaller firm segment, entry and exit play the dominant role. Entry and exit provide the turnover that is critical for driving productivity growth in that segment of the firm-size distribution that is dominated by a large number of small firms. Of course, in the long run, an entrant becomes an incumbent and contributes to the productivity gain of this sector.

\section{Innovation and Small Firms}

Entrants are often seen as providing the dynamic new force in an industry that leads to change. Productivity growth is one way in which this is manifested. But changes in productivity are the result of either product or process innovation. While there are few studies on the effect of new firms on productivity growth, much more attention has been paid to the role of small firms on innovation.

Until recently, most economic studies of innovation have concentrated on testing the theory, which is commonly associated with Schumpeter, that large firms are the foundations upon which innovation is built. Schumpeter (1939, p. 69-70) also emphasized the important role that the entrepreneur played in creating new firms that are portrayed as being responsible for introducing many new ideas; but his later book (1942) contained the thread that large firms possessed an advantage when it came to research and development and that R\&D had become increasingly critical to the innovation system.

The issue of whether large firms have an advantage in the research and development process occupied most of the attention of the North American economics profession who studied the role of firm size in the innovation system in the post-war period. Scherer (1992) summarizes this literature and concludes that the evidence for a large-firm scale advantage is not strong. The evidence suggested that $R \& D$ as a proportion of sales increased up to the middle size groups but did not continue to do so for the largest firms. Unfortunately, this literature did leave the impression that smaller firms were not very innovative-at least when it came to their role in R\&D expenditure-since scale economies existed in the smaller size classes. The result of this work was to indirectly attribute a relatively unimportant role in the innovation process to small business.

R\&D is, of course, an indirect measure of innovativeness since it focuses on an input rather than an output. If there were a one-to-one relationship between $R \& D$ and innovation, it would be a 
sensible proxy that could be used to evaluate the respective innovativeness of any two groups of firms. But there is good reason to believe that it is a particularly poor measure for comparisons between large- and small-firms. Schmookler (1959) suggested that statistics on formal R\&D expenditure probably missed a larger proportion of innovative activity related to R\&D in small than in large firms. Subsequent studies confirm his suspicion. Kleinknecht $(1987,1989)$ confirmed that official statistics do indeed miss more informal R\&D activity in small than in large firms in the case of Holland. ${ }^{17}$ For Canada, Baldwin (1997) finds that the R\&D of small firms, more than large firms, tends to be done on an occasional basis and, therefore, not to be caught by the formal definition that is used to collect R\&D statistics. ${ }^{18}$ When both the R\&D that is done on an ongoing basis in formal R\&D laboratories and that which is informal and is performed in production or engineering departments is counted, small and large Canadian firms differed, but not by nearly so much if only formal R\&D were used. Some $86 \%$ of large firms (500+ employees) in the Canadian manufacturing sector performed any form of R\&D, while some $76 \%$ of small firms (20-100 employees) did the same. The relative percentages doing so on an occasional basis were $33 \%$ for large and $43 \%$ for small firms, while it was $53 \%$ and $32 \%$ for ongoing continuous efforts in favour of large firms.

But even these numbers are misleading. The stress that has been placed on R\&D has skewed the debate on the importance of small firms and caused it to focus on only one aspect of the innovation potential inherent in a firm-R\&D. This is an input to innovative activity, where scale economies are probably important_at least up to mid-size firms. The exclusive use of R\&D measures therefore leads to the impression that small firms have a general cost-disadvantage with regards to innovation. This emphasis on $\mathrm{R} \& \mathrm{D}$ neglects the other ways in which innovation occurs. Evidence from innovation surveys (e.g. Baldwin and Da Pont, 1996) indicates that the R\&D process is only one of many that contributes to innovation. Substantial discoveries have been made outside of $\mathrm{R} \& \mathrm{D}$ labs that have led to important innovations. It is in engineering or processing divisions that many new technological breakthroughs are made (Mowery and Rosenberg, 1989). Using R\&D to define a technologically advanced firm will neglect firms that make their advances outside of organized R\&D labs. Others have made the same point using industry-level data on different aspects of the innovation process. Audretsch (1995) examines the connection between measures of innovation, $R \& D$ inputs and patents and observes that they do not measure the same economic phenomenon.

The validity of comparisons using the R\&D intensities of large and small firms is implicitly based on the concept that firms are homogeneous entities and that to be equally effective, they should look alike. Yet small firms are not miniature replicas of large firms. Small firms are disadvantaged in those areas where scale matters-production processes, the organization of information, the training of labour, the financing of capital. Despite this, small firms coexist with large firms. They do so because small firms possess strengths in some areas that large firms do not (Rothwell, 1989; Rothwell and Zegveld, 1982). Small firms have an advantage in terms of their flexibility and speed of response. Small firms can experiment with product changes-especially on the quality side. A survey of the strategies pursued by new firms finds that quality, customer service, and flexibility in

\footnotetext{
${ }^{17}$ See also Santarelli and Sterlachinni (1990).

${ }^{18}$ Kleinknecht et al. (1991) points out that the international Frascati manual, which is meant to govern R\&D collection efforts, specifically excludes occasional R\&D.
} 
responding to customer needs receives the greatest emphasis (Baldwin et al., 1994). Small firms often stress a niche strategy by offering better levels of customer service and showing flexibility by varying the product quality slightly to better meet the needs of customers. They do the same when it comes to innovation by responding to opportunities to bring to market new products with a minimum of delay-by performing R\&D occasionally when a problem needs to be addressed. The advantage of the flexibility of smaller organizations is recognized by large organizations that have attempted to develop small entrepreneurial groups so that they could combine the advantages of scale or scope economies with the dynamics of small research teams.

The fact that small firms do not focus as heavily on R\&D as do large firms does not mean that they are not innovative. Small firms look to other sources for their innovative ideas. The Canadian 1993 Innovation Survey (Baldwin, 1997) finds a significant difference between large and small firms as to the sources of ideas for innovation. Small firms (20-99 employees) tend to rely less on R\&D but more on their production units for their innovations than do large (500+ employees) firms. They also tend to rely more on customers. Small firms then form networks with others through customer relationships and incorporate innovations through their production divisions. Large firms are more likely to perform R\&D and while they too develop networks, these interfirm relationships are based relatively more heavily upon exchanges with related or sister firms.

Small and large firms then have different innovation regimes. Whether they are more or less innovative needs to be determined by comparing the outputs of their innovative processes to the inputs. To this end, researchers have attempted to measure the number of innovations produced by small versus large firms. This has been done in several different ways. Historical studies (Jewkes, Sawers and Stillerman, 1959) have argued that major 20th century innovations often came from small firms, ${ }^{19}$ though as Freeman (1982) notes, the ultimate commercialization depended in many cases upon large firms. Hamberg (1963), Peck (1962) and Enos (1962) have also emphasized the importance of small research laboratories at the early stages of the commercialization process.

Case studies of the history of a small number of innovations are rich in detail; but they do not easily permit generalizations about the population of innovations. Such generalizations require large-sample databases. Several of these have been constructed and employed to compare the innovativeness of small and large firms. Rothwell (1989) uses a database of major innovations that was assembled by the Science Policy Research Unit at the University of Sussex. The list of innovations was assembled by a panel of 'experts' and consisted of 4,378 innovations made over the period 1945-83. Rothwell reports that the small-firm (1-199 employees) share of innovations contained in this database increased from about $22 \%$ during the period $1965-69$ to some $38 \%$ by 1975-79.

A second major database has been created by the Futures Group for the Small Business Administration (SBA). ${ }^{20}$ This database consists of 8,074 innovations made in manufacturing industries that were put together from 1982 technology, engineering and trade journals. A more

\footnotetext{
${ }^{19}$ Rothwell (1989) notes that Hamberg(1963), Peck (1962) for aluminium and Enos (1962) for petroleum also delineate the importance of innovations originating in small firms.

${ }^{20}$ See Acs and Audretsch (1990).
} 
inclusive definition of innovation is used in the SBA database than was used for the UK SPRU database. When the innovations were classified by degree of originality, over $85 \%$ were classified as being modest improvements designed to update existing products-less than $12 \%$ involved significant innovations (Audretsch, 1995, Table 2.7). Defining small firms as those with less than 500 employees, Audretsch divides the population into innovations created by small and large firms at the industry level. In many industries, small firms contribute more innovations in total than do large firms. At least in terms of numbers of innovations, small firms are important innovators.

The issue of the importance of small as opposed to large firms in the innovation process does not just turn on the share of innovations produced by each group. In a world where resources are constrained, efficiency is relevant. Whether small firms are the most efficient innovators requires a yardstick for defining efficiency. One such measure is the ratio of innovation output to inputs-a type of productivity measure. Two such input measures have been utilized-one using employment and the other R\&D as input measures. Freeman (1982) noted that the small-firm share of innovation in the UK from 1945-81 was $12 \%$, whereas its production and employment shares as of 1963 were $19 \%$ and $22 \%$, respectively. ${ }^{21}$ Rothwell $(1989$, p. 56) also reports that the SPRU data show that the innovation share of small firms divided by their employment share is consistently less than unity. In contrast, the innovation share divided by the R\&D share is greater than unity. The former indicates that small firms are relatively inefficient, while the latter indicates that they are relatively efficient. The fact that R\&D may be understated for small firms makes the latter comparison imperfect. But then so too is the former, since not all employment is devoted to innovation and the proportion probably differs between small and large firms. These ratios then provide mixed results for the UK.

In contrast, the results for the U.S. show a small-business sector that is more dynamic. For example, Freeman (1982) compares UK and U.S. data ${ }^{22}$ for six sectors and finds that the U.S. small-firm share of innovations is slightly larger than for the UK. Moreover, Audretsch (1995) uses efficiency measures similar to those employed by Rothwell to argue that the U.S. small-firm sector is more innovative than the large-firm sector. Using the U.S. SBA innovation database, Audretsch defines efficiency as the number of innovations in small firms divided by the number of employees in small firms and reports that in fourteen of eighteen industries, this measure was larger for small than large firms.

While these studies show remarkable small firm innovative activity, they have certain shortcomings. First, the interpretation of the efficiency measure that is used is problematic. Since employment and sales are closely related, if large firms have a relatively large employment share compared to their share of innovations they also have a large sales share compared to their innovation share. A large firm that accounts for a significant share of final demand would have a greater impact on consumer welfare, ceteris paribus, than a small firm for each innovation. Thus where firms have a larger share of employment than of innovations, they will also have a larger share of output than of innovations. But far from implying that large firms are 'inefficient', this means that the innovative output of these firms, arguably, has a greater impact. Moreover, the concept of efficiency that is used in the Audretsch comparison is too narrow-because output is

\footnotetext{
${ }^{21}$ See Freeman (1971) for an earlier study.
}

22 The US data come from Kleinman (1975). 
not accurately measured in terms of the number of innovations alone. An appropriate measure has to take into account the volume of sales and a simple measure of innovation numbers per employee does not do so.

A second shortcoming of these studies is the definition of an innovation that is used. Although focusing on the outputs of the innovation process provides an inherently more satisfactory procedure for comparing small and large firms than just focusing on inputs, this approach is not without drawbacks. The creation of lists of innovations constructed by SPRU and the SBA involves considerable subjectivity - even when done by a panel of experts. Innovations range from the most novel and original to the more mundane and imitative. Determining whether small or large firms are more innovative could depend on the cut-off point used to distinguish between the important and the less important innovations during the collection of innovation data. The difference between the SPRU results for the UK and the SBA results for the U.S. could simply be that the U.S. innovation list, coming from trade journals rather than 'experts', contained more innovations that were less pathbreaking and small firms tend to concentrate more on these types of innovations. Moreover, the comprehensiveness of the list of innovations generated by these literature-based searches is difficult to evaluate. One bias is readily acknowledged. Lists of innovations that are drawn from trade publications will be dominated by product innovations and will under-represent process innovations (Kleinknecht, Reijnen and Smits, 1992). Since there is evidence to suggest that small firms tend to focus more on product than process innovations (Cohen and Klepper, 1996b), this will bias the small- versus large-firm comparison in favour of small firms.

Two European studies that are based on trade-journal surveys confirm the SBA result that the novelty of innovations taken from trade-journals covers a wide gamut. Of a sample of 1,242 domestically developed innovations introduced in the Netherlands in 1989 , only $3.6 \%$ were totally new, 49.2\% were modestly improved and 41.3\% involved simply a product differentiation (Kleinknecht, Reijnen and Smits, 1992). Fleissner, Hofkirchner and Pohl (1993) found that of 1,355 innovations introduced by both foreign and Austrian enterprises in Austria during 1989, only $17.5 \%$ involved completely new products, $20.5 \%$ involved moderately changed products, $25.2 \%$ involved changed parts, and $29.6 \%$ were simply product differentiation.

While the innovation databases created by trade journals or experts offer what is, potentially, a more comprehensive coverage of innovations than the selective approach pursued by case studies, they do not cover the population of firms nor do they allow comprehensive data on the firms who are innovating to be collected-except through follow-up interviews. In contrast, innovation surveys do, however, provide a way of profiling the population of firms and can provide a richer comparison of the innovative tendencies of small and large firms. Firms in innovation surveys are asked to indicate whether they produced an innovation. These surveys potentially are more inclusive in that they can cover an entire population of firms, both large and small. ${ }^{23}$ These

\footnotetext{
${ }^{23}$ The innovation surveys do suffer a potential problem in that they rely on a firm to identify itself as an innovator or a non-innovator and the type of innovation being introduced. This problem can be tempered by collecting additional information on the type of innovation that is being reported-as was done in the 1993 Canadian innovation survey.
} 
surveys are also more inclusive investigations in that they do not rely upon a specific list of highly visible innovations, which may depend upon the particular set of 'experts' chosen.

Their advantage when it comes to inclusivity may create a problem if it leads to a lack of precision as to what constitutes an innovation-though this problem can be addressed since the survey can investigate the extent to which the innovations being reported were indeed major. For example, the 1993 Canadian innovation survey investigated whether the major innovation of the firm was a world-first, a Canadian first or fell into a residual category (Baldwin and Da Pont, 1996). Only $16 \%$ fell in the category of world-firsts. More importantly, the innovation regime (the profile of its technological capabilities) varied substantially across the various innovation types. This implies that there is a continuum of firms with different capacities within an industry-that the population of innovators is heterogeneous, not homogeneous-and that the types of inputs producing the innovation are a function of the novelty of the innovation.

This heterogeneity is particularly evident when small and large firms are compared. The results of the Canadian innovation survey (Baldwin, 1997) indicate that small firms are both more and less innovative than large firms - depending upon the criterion that is used. The likelihood that a firm has produced an innovation over a three-year period is less for small firms than for large firmssome $30 \%$ for firms between 0 and 19 employees, $40 \%$ for firms between 20 and 99 employees, and over $63 \%$ for firms above 500 employees. Small firms suffer more of a disadvantage with regards to product than process innovations, thereby confirming Cohen and Klepper's hypothesis (1996a, 1996b) that cost-spreading probably gives larger firms a comparative advantage in process innovation. It is also the case that small firms are less likely to have a novel innovation, since only $11 \%$ of innovations for firms between 20 and 99 employees were world-firsts, while this figure was $30 \%$ for firms with over 500 employees.

While a small firm is less likely to be an innovator than a large firm, small firms as a whole produce more innovations than large firms do. The innovation propensity that is quoted above for small firms is one-half to two-thirds that of large firms; but small firms are ten to twenty times as numerous. Therefore, small firms as a group contribute a significantly larger proportion of innovations than do large firms. Small firms may be less inclined to innovate but their sheer weight of numbers means that as a group, they provide an important stimulus to innovation.

Since the R\&D activities of firms are linked in the Canadian survey to data on innovation, the extent to which R\&D performers report an innovation can be used as a rough measure of efficiency. In this respect, small firms are similar to their larger compatriots. Both large- and small-firm performers of $R \& D$ are about as likely to introduce an innovation.

The evidence from the Canadian innovation survey provides a more comprehensive view of the relative innovativeness of small and large firms. It also refocuses the debate from one that tries to establish winners to one that better understands the different roles that small and large firms play. The Canadian evidence not only shows that large and small firms differ but also that even small firms are heterogeneous. One of the group of small firms resembles large firms in that they perform $R \& D$ and generate new products and processes (relatively more of the former than the latter) primarily through their internal efforts. The second group of small firms consists of those 
who rely upon customers and suppliers for their sources of ideas for innovation. Large firms, by way of contrast, tend to rely more heavily on R\&D. While they too rely on networks for ideas, their networks focus more heavily on relationships with other firms that are affiliates.

The finding that firms are heterogeneous is important since much of the literature that tries to decide whether large and small firms are more innovative implicitly assumes that the two size groups are substitutes-because the policy implications for most analyses are usually framed in terms of whether size should be encouraged or discouraged by antitrust policy. This approach is inappropriate if small and large firms fulfil different functions.

The life-cycle model that has been developed by Shimsoni (1970), Abernathy and Utterbach (1978), Gort and Klepper (1982), Klepper and Millar (1995), and Klepper (1996) rationalizes the reason for the coexistence for small and large firms. Small firms often excel in the early stages of an industry when product standards are still in a fluid state, when competition is based on new features, when entry is high and so is exit, and when production processes have not yet stabilized. At a later, more mature stage, when the basic product has stabilized, firms become larger as the focus on price becomes more important and process innovation becomes the center of firms' attempts to reduce costs. In these models, small and large firms coexist-but only because they are at different stages of the life-cycle. Small and large firms then have a symbiotic relationship. Small firms begin the innovation cycle by taking an invention to the first commercialization stage, only to have larger firms take it over at a subsequent stage in order to successfully mass market the product.

There are other explanations why small and large firms coexist. First, firms may coexist in the same industry with some adopting a leader and others pursuing a follower strategy with regards to innovation (Nelson, 1987). Although some models implicitly assume that larger firms will adopt new technologies first and small firms will follow (Davies, 1979), there is empirical work to suggest that in some situations smaller firms are quicker to adopt new technologies, i.e., in the steel industry Oster (1982). ${ }^{24}$ Second, networks of firms are linked together across industries in the production of any one product. Some will consist of large firms from industries where scale economies dominate, others will consist of smaller firms, in industries where scale is less important. Productivity gains measured at the level of the final product will depend upon productivity gains and innovation that is carried out in each of the industries that contributes to the final product. The firms at the different levels form synergetic relationships that benefit one another. In some cases, innovation in the vertical chain of production is driven from below by suppliers. In other cases, it is driven from above by customers. Small firms often link up with other firms in their network of production relationships to introduce new processes or products.

Small firms then play a different role than large firms. To understand that role, we need more detail on their strategies and activities. In the following section, we provide this by examining the innovation activities of new entrants.

\footnotetext{
${ }^{24}$ Mansfield (1977) shows that lower market concentration generally speeds up diffusion and concludes that this is consistent with his extensive work on the diffusion of innovations (1968). See also Nabseth and Ray (1974) for a set of case studies.
} 


\section{Entrants and Innovation}

The empirical work on small-firm innovation capability has had to wrestle with a paucity of usable data on innovations. Exercises to measure innovations using experts or trade journals have provided data on innovative tendencies; however, in doing so, they have tended to reduce the world of innovation to a single dimension.

Innovations are not easily pigeonholed in one compartment. Some innovations involve new products, others new processes. Some firms will focus on the use of advanced technologies. Others will incorporate new ideas by embodying skills in their employees who will in turn produce new products. Technology and skills will come in different combinations.

The variety of innovations that are being continuously introduced means that there is no single measure of innovativeness that innovation surveys or trade-journal searches should be expected to yield. It is not sufficient to argue that this could be resolved by specifying that it is only major innovations that should be included in the definition of an innovation since it is only major breakthroughs that should interest us. First, this still leaves the problem of defining 'major'. Second, this position ignores the important contribution that marginal innovations make. Hollander (1965) for example, studied the course of productivity growth in Dupont's rayon division and found that much of its productivity growth was attributed to marginal innovations. Freeman (1982) notes that substantial progress is made in the way of incremental process innovation and these types of improvements tend not to be captured in major event studies that focus on 'innovations'. Incremental innovations are not measured by patent statistics since they are not patented or by historical studies that focus on major breakthroughs.

If we are to understand the importance of new, small firms in the innovation process, it is essential to move beyond the very simple partial analysis based on a single variable like R\&D or a single definition of innovation and develop a classification scheme based on a number of innovative competencies. Only by doing so can we fully appreciate the complexity of an innovation process that is multidimensional rather than unidimensional.

To do so, we make use of firm-level data on entrants to examine the nature of their innovative capabilities. The firm-level data are taken from The Survey of Operating and Financial Practices of Entrants performed by Statistics Canada in 1996. The focus on new firms permits us to examine the innovative capabilities of entrants as opposed to small firms in general. The richness of the survey database allows both output and input-based measures of innovation, technological and skill-based competencies of smaller firms to be developed.

The survey focused on new entrants that emerged from their early childhood and survived to their early teens, years 11-14. In light of the high death rate of new firms, these are the more successful entrants. The frame consisted of all entrants to the commercial sector (both goods and service) in the period 1983-86 that survived to 1993; the survey was conducted in 1996. The sample 
included 3,991 firms from both the goods and service sector. The response rate to the survey was $80 \%$.

The survey provides a broad overview of the financing and operating practices of entrants. The questionnaire contains information on 1) management-the extent of managerial and industry experience and the degree of ownership in the firm 2) the nature of the competitive environment-whether products quickly become obsolete, whether production technology changes rapidly, whether the threat of new entry is high 3) the firm's competencies in the area of management, technology, human resources, financing, marketing and production, with special attention paid to various facets of competencies in each area 4) the extent of financial planning 5) the importance of investment in $\mathrm{R} \& \mathrm{D}$, technology, and training 6) whether the firm engaged in formal training and 7) the manner by which various activities were financed.

In order to study the innovative capability of successful entrants, we make use of questions taken from four areas-on the innovative capabilities of firms, on their human-resource competencies, on their technological capacities, and on their competitive strategies. Each of these will be used to define the extent to which new firms followed an innovation, a technovation (an advanced hightech input strategy) or a knowledge (a skill-based) strategy.

There are two types of questions that are used to provide information on the competencies of entrants. First, there are questions that characterize an entrant as following certain strategies-as producing a product innovation, as having formal training, or the percentage of investment in $\mathrm{R} \& \mathrm{D}$ or in training. These take on $0-1$ values or are expressed as percentages. Second, there are answers to questions about the entrant's emphasis placed on factors, such as R\&D capabilities or training activities, that contributed to the ongoing success of the firm. These questions were scored on a five-point Likert scale of 1 (low importance) to 5 (high importance). These are used here to gauge the entrant's competencies. ${ }^{25}$ In what follows, entrants are deemed to possess a particular competency or to be stressing a particular strategy if they score that strategy as 4 or 5 on the five-point Likert scale.

\footnotetext{
${ }^{25}$ Where possible the two sets of questions were cross-tabulated in order to validate the nature of the Likert scale. For example, there is a high correlation between the importance given to R\&D and the \% of investment devoted to $\mathrm{R} \& \mathrm{D}$ - or the score given to training and whether a firm had implemented a formal training program (See Baldwin and Gellatly, 1998). This has also been found in previous surveys that ask firms to score their competencies and to indicate the intensity of their activities (Baldwin et al., 1994).
} 


\subsection{Innovative Competencies}

In order to catch the diversity of innovative activity taking place, the stress that new, small firms place on innovation is measured with 10 different variables. Each captures a different, though related concept of innovation.

Several of the measures make use of a question that asked whether an entrant had introduced an innovation. An innovation was defined as the introduction of a new or improved product or process, but not the introduction of aesthetic changes that did not affect the technical construction or performance of the product. These innovations were, in turn, characterized as being either entirely new products, modifications of existing products, entirely new processes, or modifications of existing processes. Finally, entrants indicated whether these innovations were protected with intellectual property rights. The latter type of innovations have been found previously to be the most innovative in the sense of being the most novel (Baldwin, 1997). Combinations of these measures are then used to define whether the entrants were introducing innovations of varying degrees of novelty and importance.

These variables are:

INGEN—whether an entrant reports any innovation.

INIMP1-whether an entrant reports an innovation and it is protected by an intellectual property right such as a patent or the firm reports that a strategy of protecting its innovations with intellectual property is important or very important (a score of 4 or 5). Baldwin (1997) finds that the most novel innovations are those that tend to avail themselves of intellectual property protection.

INIMP2-whether an entrant reports an innovation that is either a completely new product or a completely new process.

INPROD—whether an entrant is a product innovator.

INPROC-whether an entrant is a process innovator.

INCOMP—whether an entrant is both a product and a process innovator.

Innovation is also measured by the emphasis that is given to a prime (though not the only) input to innovation—research and development. The variables are:

INRD—whether an entrant scored 4 or 5 on the importance given to R\&D capabilities.

INIMP - whether an entrant's percent of investment devoted to R\&D was above the median of all other entrants who had positive investment in R\&D. 
Finally, the innovative tendencies are measured by the scores that are given to the importance that an entrant attributes to different competitive strategies that involve a broader concept of innovation. The first measure is the frequency of new product introduction. It complements the earlier innovation measures by focusing on frequency of product improvement. By definition, a new product can involve minor product differentiation changes and its coverage is broader than that of an innovation, but it is the concept captured by trade-journal lists that includes a substantial amount of product differentiation in their innovation counts. The variable used is:

INFREQ-whether an entrant scores 4 or 5 on the extent to which it frequently introduces new/improved products.

The second takes a broader approach and examines the extent to which entrants focus on providing a different type of innovation-what might be referred to as a traditional innovation involving customization and quality variation. The majority of small firms cannot compete directly on prices with larger firms because of the cost disadvantages associated with size. Instead, they stress a niche strategy by varying the quality of product, offering slightly better levels of customer service, showing flexibility to customer needs or customizing their product for individual customer requirements. The value of a product to consumers is a function of its quality. All firms, but small firms in particular, are constantly experimenting with variations in quality to attract customers. These experiments all involve innovations-though, in most cases, they are incremental in nature. While incremental, their importance should not be discounted. The cumulative effect of the sum of many changes at the margin can be large. The variable used to catch this aspect of innovation is:

INTRAD - whether an entrant scores at least 18 out of a possible 20 points on the importance attributed to quality, customer service, flexibility in responding to customer needs and customization.

\subsection{Technological Competencies}

Rather than focus on the output of the innovation process as we did in the last section, we can examine the existence of certain capabilities. In the first instance, we focus on whether technological innovation (technovation) in an entrant is important. Technological innovation involves a different though related dimension of innovation-the extent to which an entrant focuses on advanced technology, increases its efficiency of input use, and introduces new production processes. The variables used here are:

INTECH1-whether an entrant scores 4 or 5 on the importance attached to developing new and refining existing technology.

INTECH2 - whether an entrant scores 4 or 5 on the importance attached to purchasing others technology.

TEDEV — whether an entrant both develops/refines new technology and purchases it. 
TECOMP - whether an entrant scores 4 or 5 on the importance given to using computercontrolled processes in production.

TEINFO-whether an entrant scores 4 or 5 on using information technology for management purposes.

TEINP - whether an entrant is in the top half of all entrants who invest in technology acquisition when it comes to the percent of investment that is devoted to technology acquisition and licensing.

PROD1-whether an entrant scores 4 or 5 on improving efficiency of input use in the production process or reducing production times.

\subsection{Human Capital Development}

The final set of innovation competencies considered here are worker skills. Entrants incorporate these skills either by focusing their human-resource strategies on hiring skilled workers or by implementing training programs. In both cases, a firm's innovation competencies are facilitated by the amount of human capital that it possesses. Baldwin and Johnson (1996b) report that a human capital strategy is pursued more intensely by innovators in both the goods and the service sectors. ${ }^{26}$ In the goods sector, it is often combined with an emphasis on R\&D or the development of new machinery and equipment. In the services sector, the innovation strategy often is the human resource strategy.

The skill emphasis of a new firm is measured here by the value that an entrant attaches to recruiting skilled labour, on the emphasis it gives to training, and finally on the extent to which it implements a formal training program and invests in training. The variables are:

LABSKL-whether an entrant scores 4 or 5 on the importance given to recruiting skilled employees.

LABSCOR—whether an entrant scores 4 or 5 on the importance attached to training.

LABFOR — whether an entrant does formal training.

LABTRAIN—whether an entrant's share of investment devoted to training is positive.

LABINT - whether the percentage of investment that is devoted to training is above the median for all entrants investing in training.

\footnotetext{
${ }^{26}$ See also Baldwin, Gray and Johnson (1996) for a study of the connection between the adoption of advanced manufacturing technologies and a firm's emphasis on training.
} 


\subsection{Comprehensiveness of Innovation in the Entrant Population}

Most entrants are innovative in one or other of the ways outlined above, but the percentage of the population of entrants that are innovative differs considerably depending upon which of the summary measures is used. This is illustrated in Figure 4, which provides the percentage of entrants that would be classified as innovative using any of the previous variables.

\section{Figure 4}

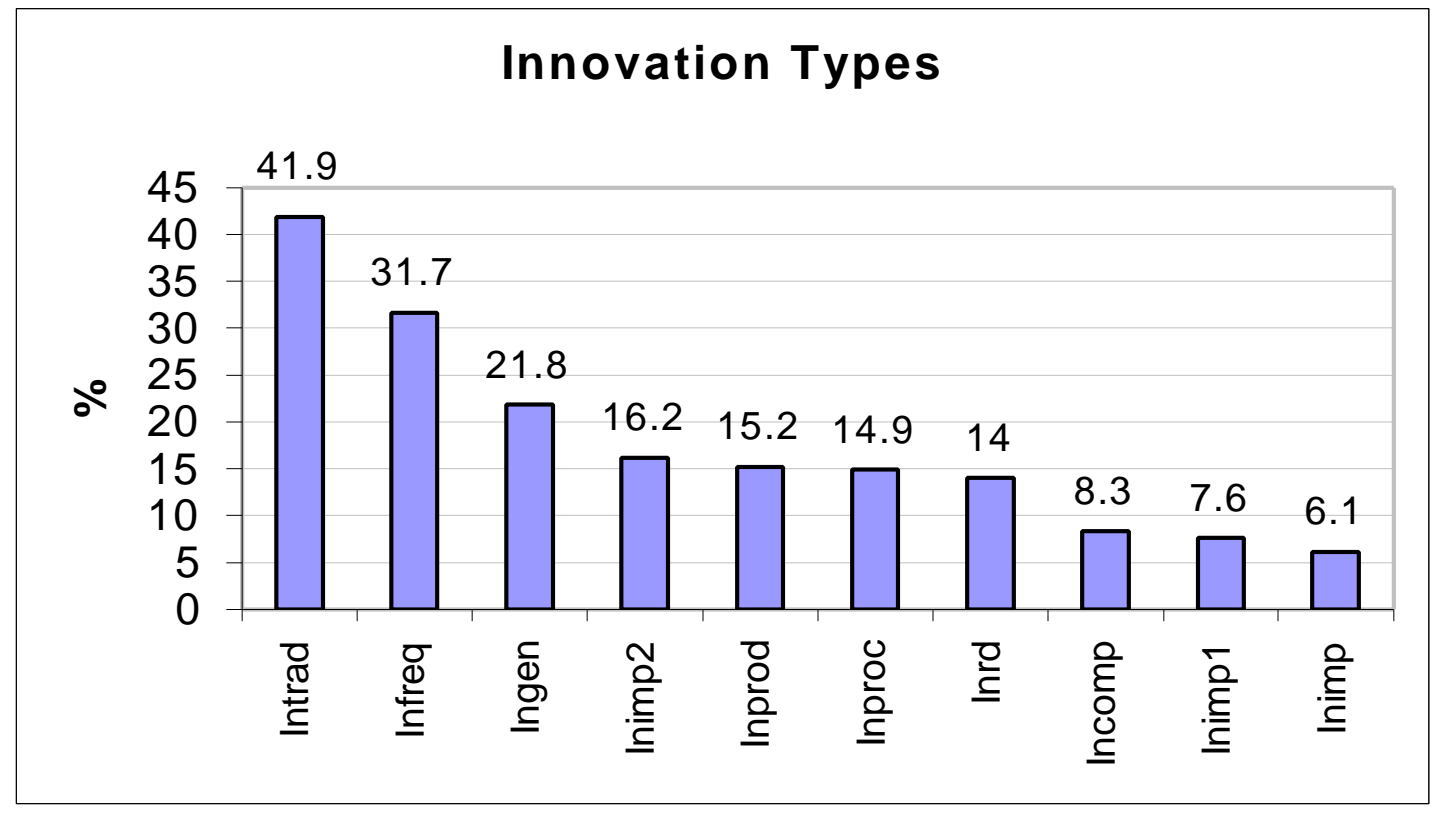

Many firms are experimenting with the type of innovation that requires bundling service or quality with a good. About $42 \%$ of the population place a heavy emphasis on varying quality to provide a unique product to the consumer (INTRAD). Somewhat fewer are introducing new products. Some $32 \%$ place more than average importance on frequently introducing new products (INFREQ). When 'new' is interpreted to mean an 'innovation', fewer firms fall into this category. Some 22\% have introduced an innovation over the 1992-94 period (INGEN). Some $14 \%$ of entrants emphasized an R\&D strategy (INRD) but some 29\% either report an innovation or that they place above average importance on $\mathrm{R} \& \mathrm{D}$-about the same percentage that emphasize the frequent introduction of new products.

When the constraint of genuine novelty is imposed on the innovation, the percentage declines by amounts that vary depending on the definition of novelty. Only $16 \%$ introduced what they consider to be an entirely new product or process (INIMP2). Some $8 \%$ introduced an innovation that was protected by formal intellectual property rights (INIMP1). Despite these differences, it should be noted that the vast majority of entrants are innovative by one or other of these standards: roughly $70 \%$ of all firms fall into one of the categories defined here. Innovation is an activity that is widely pursued. 
The various measures of the firm's technological capabilities also indicate a diversity of technological competencies. These are examined in Figure 5.

\section{Figure 5}

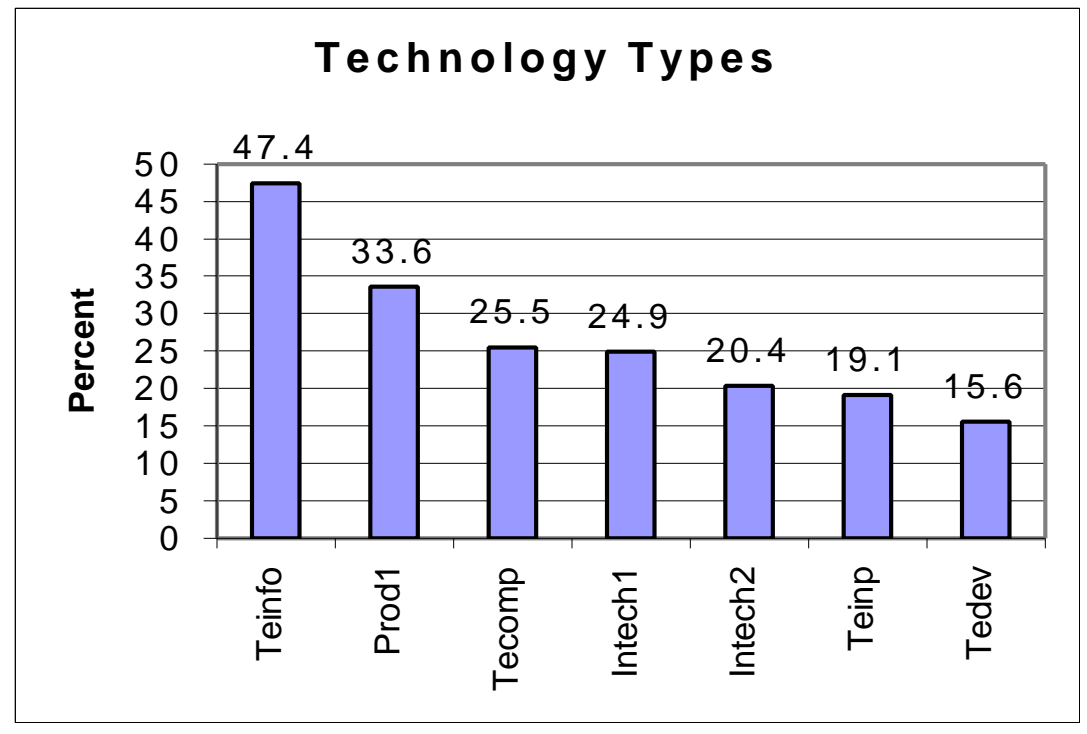

In accord with the finding of Baldwin and Sabourin (1996) that communications technologies have been expanding fastest, the largest group of firms (47\%) emphasize the importance of computer-based information technologies (TEINFO). The next largest percentage of entrants (34\%) focus on methods to reduce the cost of inputs and to reduce production times (PROD1). Roughly $25 \%$ place heavy emphasis on developing new technologies (INTECH1) or use computer-controlled processes in production (TECOMP). There are about 20\% who stress the purchase of new technologies (INTECH2). Finally, 16\% of firms both develop new technologies and purchase new technologies from others (TEDEV). Once again, a clear majority of entrants are engaged in some form of technovation; here too approximately $70 \%$ fall into at least one of the technovation categories.

There is also a large percentage of firms who stress the importance of worker skills and training. This is examined in Figure 6.

Roughly 56\% indicate that training is important (LABSCOR) and devote considerable importance to recruiting skilled labour (LABSKL). About the same percentage perform formal training to upgrade their employees skills (LABFOR). Some 52\% have implemented a formal training program. Even if we judge whether firms are performing substantial activity in this area-on the basis of whether they report that they devote part of their investment to training (LABTRAIN) $31 \%$ of new firms still are seen to be serious participants in upgrading human capital. Thus, a large percentage of entrants are part of the knowledge economy in the sense that they place a high value on human capital. 


\section{Figure 6}

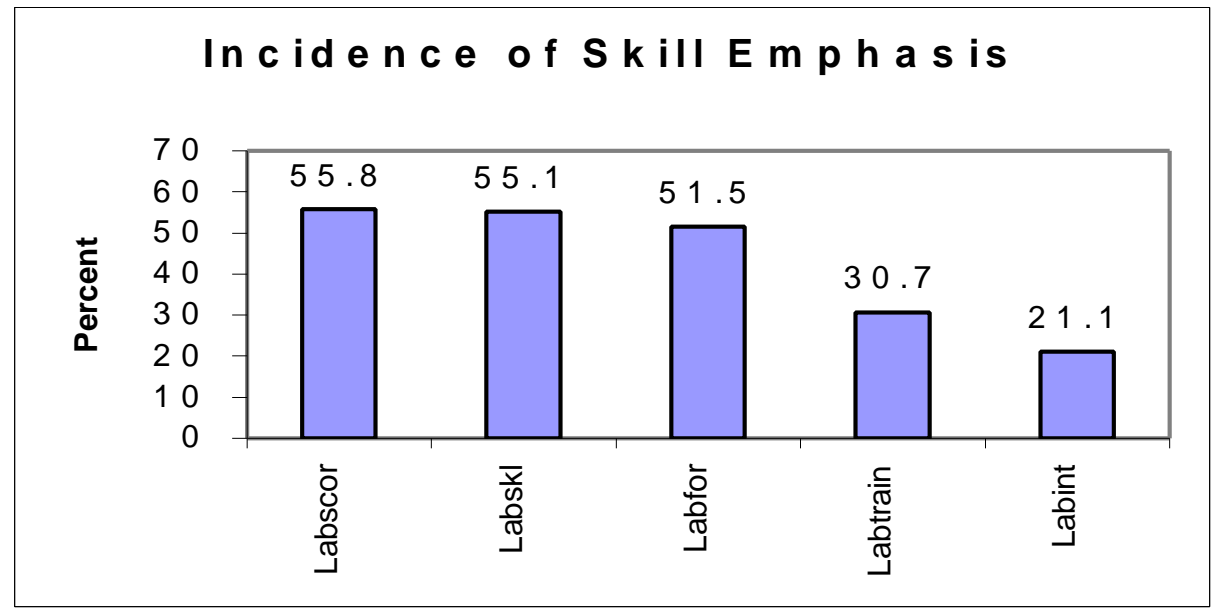

These data show that a substantial proportion of new entrants consider themselves to be either innovative or technologically advanced or to depend on skilled workers. When we consider the characteristics jointly, the percentage of entrants that fall into at least one category increases. For example, $22 \%$ of new firms report an innovation, $14 \%$ place a very high importance on R\&D and $29 \%$ report at least one of these two characteristics. Similarly, 25\% of entrants report that they develop new or refine existing technology, while $20 \%$ bring in outside technology; but some $30 \%$ perform at least one of these two. Some $47 \%$ of entrants use information technology in management and $25 \%$ use computers for process control, however, $53 \%$ of entrants exhibit at least one of these characteristics. When we expand our definitions of innovation to encompass a characteristic from more than just the innovative group, the percentage of entrants that can be said to be innovative is quite large. Some $39 \%$ report an innovation, or perform R\&D, or emphasize either the development or purchase of technology. Some $65 \%$ report one of the above competencies, or emphasize computer-controlled processes, or stress the use of information technologies.

\section{A Profile of Entrants}

The development of longitudinal databases on exit and entry have allowed us to better estimate the amount of entry taking place and to determine that this aspect of turnover shifts significant amounts of market share and changes the identity of market participants. But the longitudinal databases derived from administrative records do not contain very rich descriptions of the participants. Survey data has to be developed if we are to better understand the underlying characteristics of entrants - their competencies, not only in innovation, but also in such areas as human resource development, marketing, and management; their financial structure; their training activities; and how each of these areas relates to innovation. When survey data are developed and linked to longitudinal data on firm performance, such as sales or profitability, differences in competencies can be outlined that are related to performance differences. In the previous section, such data on innovation were presented. Here we use the same survey on entrants that was 
described above and outline the type of environment that entrants face and the connection between growth, innovation and associated competencies that innovative firms develop.

\subsection{The Competitive Environment}

The competitive environment that new entrants face affects the skills required for survival and growth. Competition has many dimensions: it depends on the type of rivals an entrant faces, the pressures placed upon it by buyers and suppliers, and the rapidity of changes in products and technology.

The type of competition in an industry is partially determined by the maturity of the market. Industries vary by the stage of development of the market for their primary product. The introductory stage occurs when the product demand is just starting to grow, but the product is unknown to many potential users; the growth stage occurs when product demand is growing and the product is becoming familiar to many potential users; the maturity stage is when product demand growth is slowing and the product has become familiar to most potential users; finally post-maturity occurs when no growth in product demand occurs and there are few potential new users. The stage of the product is expected to influence the firm because previous work (Gort and Klepper, 1982) suggests that early stages in the product life cycle involve a high degree of uncertainty. Product and technological innovations follow one another in quick succession. In later phases, the type of problems change. Reducing production costs via technological change becomes more important.

Despite the fact that successful entrants are new, successful entrants generally serve mature markets. While $29 \%$ of successful entrants are in a growing product market, $50 \%$ are in mature markets. Moreover, a greater percentage is in the post-maturity phase (18\%) than the introductory phase $(3 \%)$. As the life-cycle model would have predicted, successful entrants reported more rapid technological than product obsolescence. When asked to indicate if they felt that products quickly become obsolete and production technology changes rapidly in their industry (on a scale of 1 to 5), only $24 \%$ of entrants felt that product obsolescence was rapid in their industry (a score of 3, 4 or 5) and $41 \%$ felt that it was not. Yet, $45 \%$ say production technology changed rapidly and only $21 \%$ disagreed.

The number of competitors also serves as a measure of the amount of competition that entrants face. About $40 \%$ face between 5 and 19 competitors. Another 38\% compete with over 20 firms. However, the number of competitors is only a rough proxy for competitiveness; firms face competition from potential as well as existing competitors. Even when the number of competitors is small rivalry can be intense. ${ }^{27}$ In order to gauge the intensity of competition, entrants were asked if they disagreed or agreed with two propositions 1) that the threat of entry was high, and 2 ) that their competitors' actions were predictable. Some $41 \%$ felt their competitors' actions were easy to predict. However, some $61 \%$ of entrants felt that threats from entry were high.

\footnotetext{
${ }^{27}$ See Baldwin (1995) for data that show that intensity of competition, as measured by market share turnover, is not closely related to concentration.
} 
Customer relations also affect the nature of the competitive environment. Firms with only one customer face uncertainty due to bilateral bargaining and more volatility from the loss of customers. Firms with few repeat customers cannot build customer loyalty. Neither factor is very important for successful entrants. Over half obtain less than $10 \%$ of their revenue from one customer and over two-thirds of their customers are repeat customers.

Figure 7. Entrants' Perceptions About Their Industry Environment

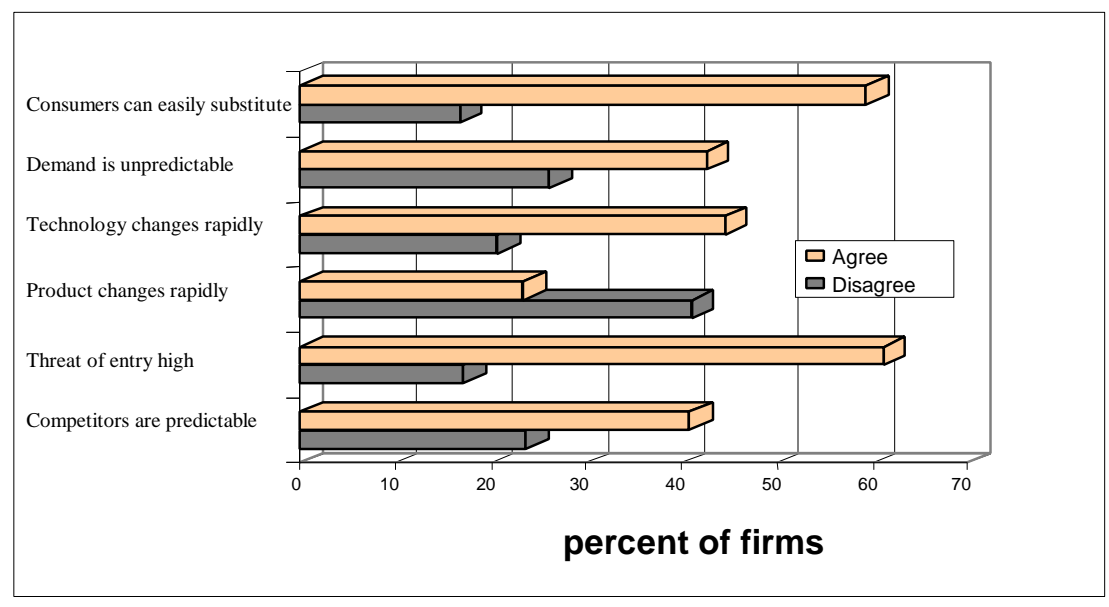

To examine the uncertainty associated with demand, successful entrants were asked if they agreed or disagreed with the statements: 1) consumer demand is difficult to predict and 2) consumers can easily substitute among competing products. The ease of substitutability represents the largest source of uncertainty, as almost $60 \%$ of entrants felt consumers could easily substitute competing products. Unpredictability of consumer demand was less of a problem; just $40 \%$ of successful entrants rated it hard to predict.

Figure 8. Percentage of Entrants Reporting Intense Industry Competition

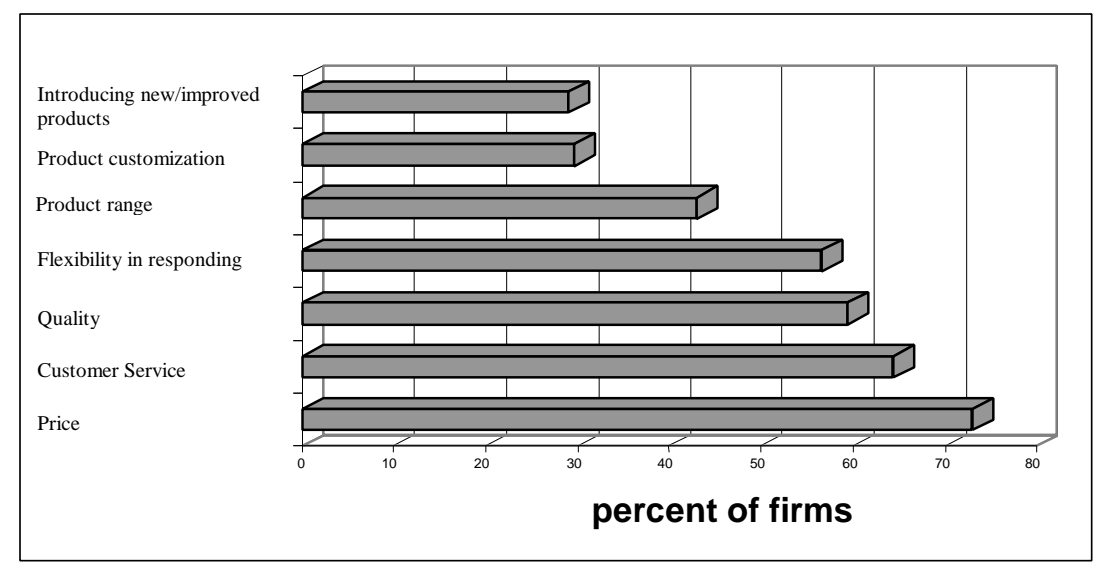

The final element that can be used to describe the competitive environment that successful entrants face is the nature of product competition. The successful entrants ranked competition in their industry on a scale of 1 (low) to 5 (high) in seven areas-price, customer service, quality, 
and flexibility in responding to customers, product range, product customization, and the frequency of introducing new/improved products. The percentage of successful entrants that ranked each area as highly competitive (4 or 5) is plotted in Figure 7. In keeping with their functioning mainly in mature markets, successful entrants report that competition in their industry is greatest with respect to price, customer service and quality. In contrast, factors that mark growth industries - customization or introducing of new products-are less important.

Do innovators face a quieter environment than non-innovators? Is innovation in the small-firm segment encouraged by concentrated market structures? The life-cycle model of entry offered by Abernathy and Utterbach (1978) or by Gort and Klepper (1982) would suggest that innovative entrants generally should be found in highly fluid, highly competitive situations.

In order to examine this issue, entrants are defined to be innovative if they are introducing new products or processes and differences are examined between entrants who are introducing new products and processes and those who are not.

How does the competitive environment of innovators differ from non-innovators? First, innovating successful entrants face more competitors; only three-quarters of non-innovative entrants face more than four competitors, compared to $87 \%$ of innovators.

Second, innovators are generally found in segments of industries where certain key aspects of competition focus on innovation. When the perceptions of innovators and non-innovators about the nature of competition that they face are compared (Figure 9), it is clear that changes that are related to innovation are far more intense in the innovators' industries. Technology is more likely to be changing rapidly. Products are more likely to face rapid obsolescence. Demand is unpredictable, probably because competitor actions are also more difficult to forecast.

It should be pointed out that in other areas competition is just as intense for both innovators and non-innovators alike. The threat of entry is high everywhere. Competitors are just as capable of switching suppliers in both groups. Both groups face the same threat that consumers can easily substitute products if they should so choose.

While small firms may have to find a niche strategy in order to survive, the innovators among them do not lead a protected existence. In general, all entrants continuously face the threat of entry. Innovators are also faced with continuous changes in new product introduction and technological change that are related to the innovative nature of the segment of the industry in which they function. 


\section{Figure 9}

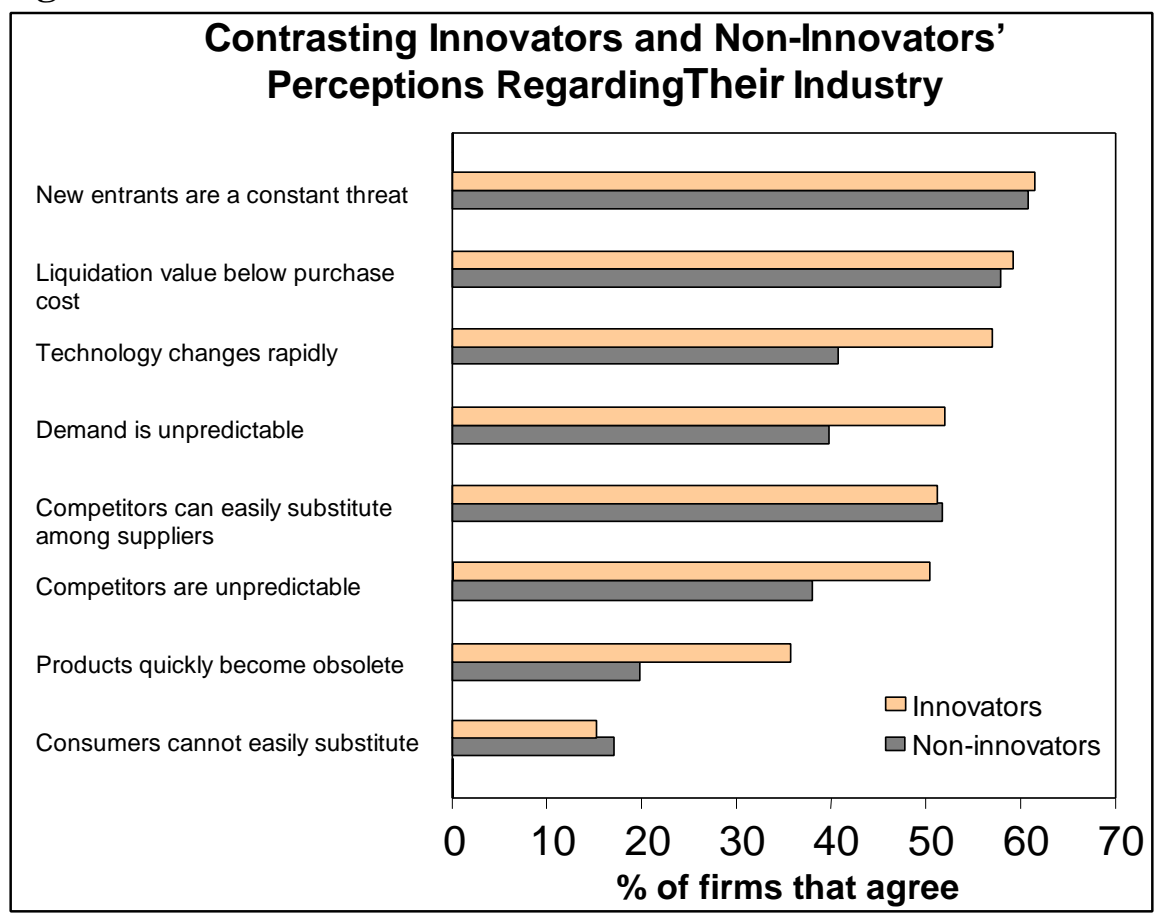

\subsection{The Focus of Entrants}

What then are the product and production strategies adopted by new firms in the face of the environment that they face? Firms concentrate their product based strategies on making their existing products as attractive as possible to consumers. There are several ways in which they do this: they can offer an attractive price, focus on quality, and strive to provide superior customer service, or offer flexibility in meeting their customers' needs. Alternatively, firms can try to alter their product line. In doing so, they might choose to customize their products, develop a product line that carries a wide range of related products, or continually expand and update their product line by frequently introducing new/improved products.

Of these strategies, successful entrants give the highest priority (scored on a scale of 1 to 5) to strategies related to quality and service. Each of the strategies here-price, quality, customer service, and flexibility in responding to customers' needs - are deemed to be important (Figure 10). Alternate strategies that involve updating, expanding or enhancing their product line are perceived to be less important by successful entrants.

The quality-oriented niche strategies are aimed at maintaining existing rather than attracting new customers. Successful entrants concentrate their marketing strategies on their existing market. This broad strategy includes specific strategies such as: 'satisfying its existing customers', or slightly more aggressive strategies directed at 'promoting the reputation of the company and its products' and 'improving position in existing markets'. Successful entrants, on average, place less value on capturing new markets, be they domestic or foreign (Figure 11). 
Figure 10. Importance of Product-Based Strategies

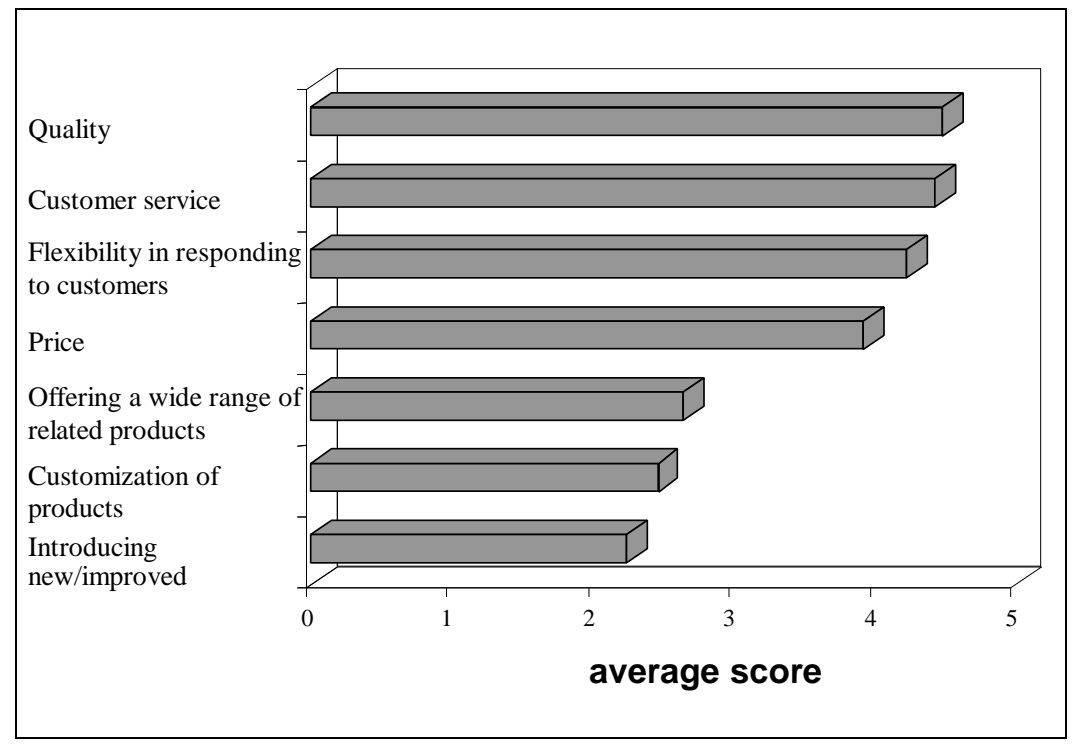

The third component to product-based competencies lies in how successful entrants make their products. They may seek to improve their production by doing it better, doing it faster, doing it more efficiently, or using better inputs. To do so, they may aim to reduce their use of material inputs; they may strive to reduce their production times; they may focus on the functioning of their production processes by introducing integrated computer controlled processes; or they may stress the importance of using high quality suppliers.

\section{Figure 11. Importance of Market-Based Strategies}

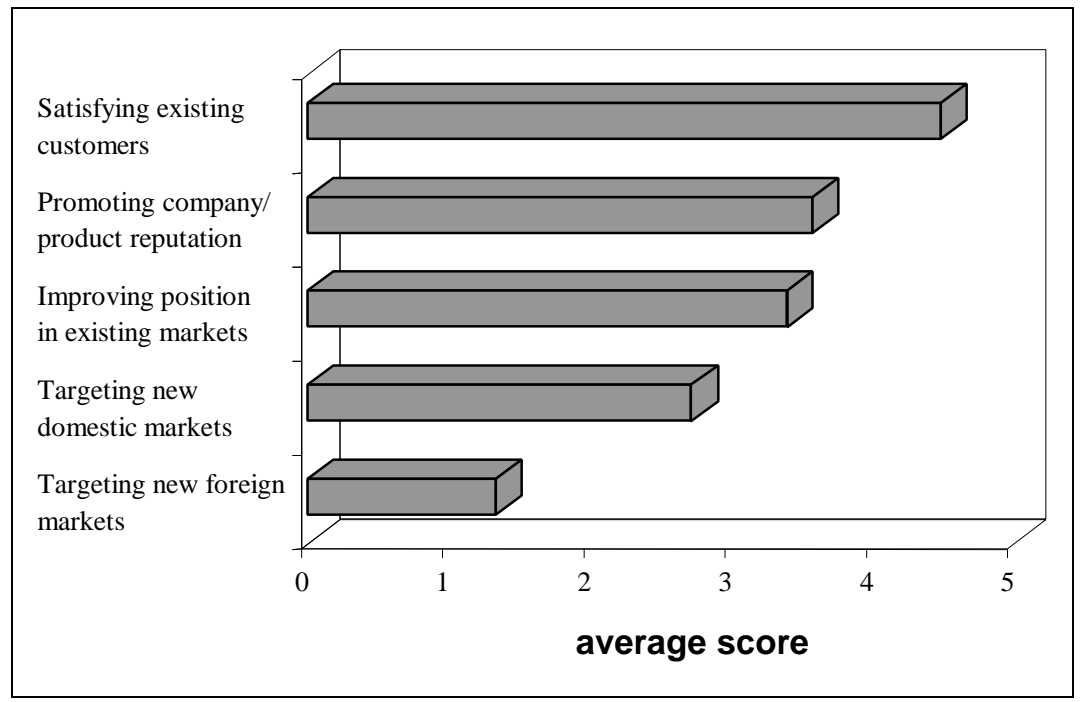


Corresponding to the stress that successful entrants give to quality as part of their product strategy, 'using high quality suppliers' is rated the most important production strategy (Figure 12). Improving efficiency of input use is next in importance, followed by reducing production times and using computer controlled processes.

Figure 12. Importance of Production Strategies

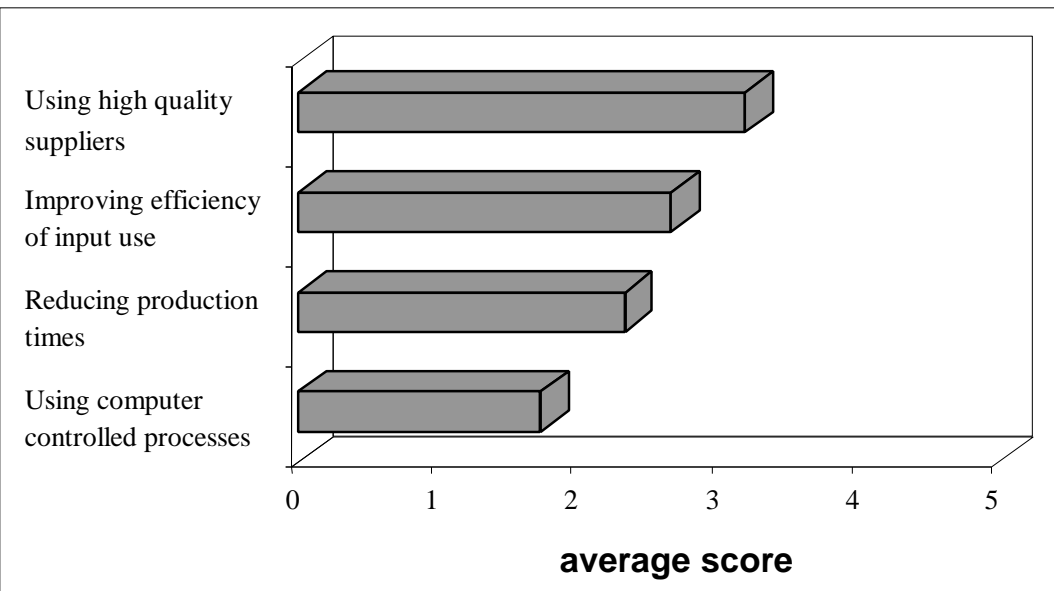

This picture of emerging successful entrants confirms the finding of other studies on small firms (Baldwin et al. 1994, and D'Amboise, 1991). The success of small firms depends on their ability to produce a high quality output, their comparative advantage is the flexibility that allows them to provide quick and efficient service. Successful entrants develop a customer-oriented business focus. Their product strategies are aimed at enhancing the attractiveness of their current products in their existing market: they focus on quality and responsiveness to customer needs; and their process strategies are concentrated on improving the efficiency and quality of the production process.

\subsection{Growth of Entrants and the Importance of Innovation}

We have already demonstrated that despite the emphasis that the economics literature has placed on the connection between innovation and firm size, small firms and entrants in particular demonstrate many different types of innovative behaviour. Nevertheless, small firms do face a highly competitive environment as demonstrated above and there are those who argue that competition does not encourage innovation. We can investigate whether this is so by asking whether it is the most innovative entrants that succeed. To do so, we investigate whether innovation is rewarded by faster growth. ${ }^{28}$

\footnotetext{
${ }^{28}$ In order to investigate the differences between faster and slower growing firms, we separate firms into two groups based on the annual average real growth in revenue from their first full year to 1993.
} 
Faster growing entrants are found to be more innovative than slower growing entrants in several different ways. They are more likely to invest in technology and R\&D (Figure 13). These investments in inputs to the innovation process are rewarded: faster growing entrants innovate at almost twice the rate of slower growing entrants.

Figure 13. Differences in the Percentage of Entrants Investing and Innovating Between Faster and Slower Growing Entrants

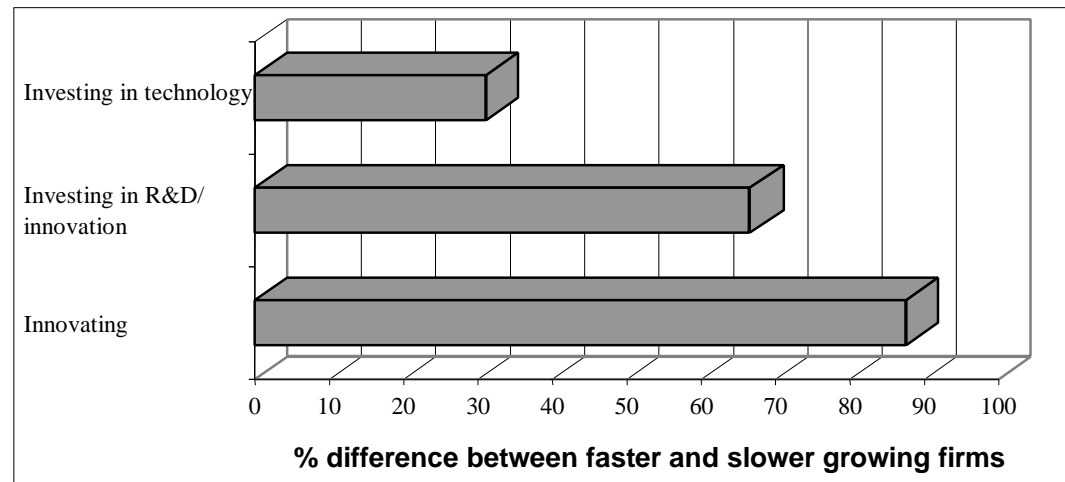

Faster growing entrants are more innovative in a number of other associated ways. They are more likely to introduce new or improved products and to seek out new markets, while at the same time striving for efficiency gains through process innovation.

Faster growing entrants rate almost all of the product-specific strategies higher than other entrants. They are most distinguished from slower-growing entrants in the value they place on product innovation-related strategies such as introducing new/improved products, offering a wide range of products, or customizing their products (Figure 14).

It is important to note that innovative strategies do not replace attention to enhancing existing products. Growing entrants also place more value on customer service, quality and flexibility in responding to customer needs. Growing entrants do not maintain unchanged product lines; rather they focus on introducing new products that are of a higher quality and on improving the delivery of the product.

The innovative stance of growing entrants is evident in their marketing strategy as well. Growing entrants place significantly greater emphasis on expanding their market reach (Figure 15). They place more emphasis on improving their position in existing markets as well as targeting new ones. Once again, the emphasis on attracting new customers does not occur at the expense of marketing strategies designed to satisfy existing customers. Growing entrants are not less attentive to their existing customers-attention to existing customers just does not discriminate the faster growers from the slower growers. 
Figure 14. Differences in the Importance of Competitive Strategies Between Faster and Slower Growing Entrants

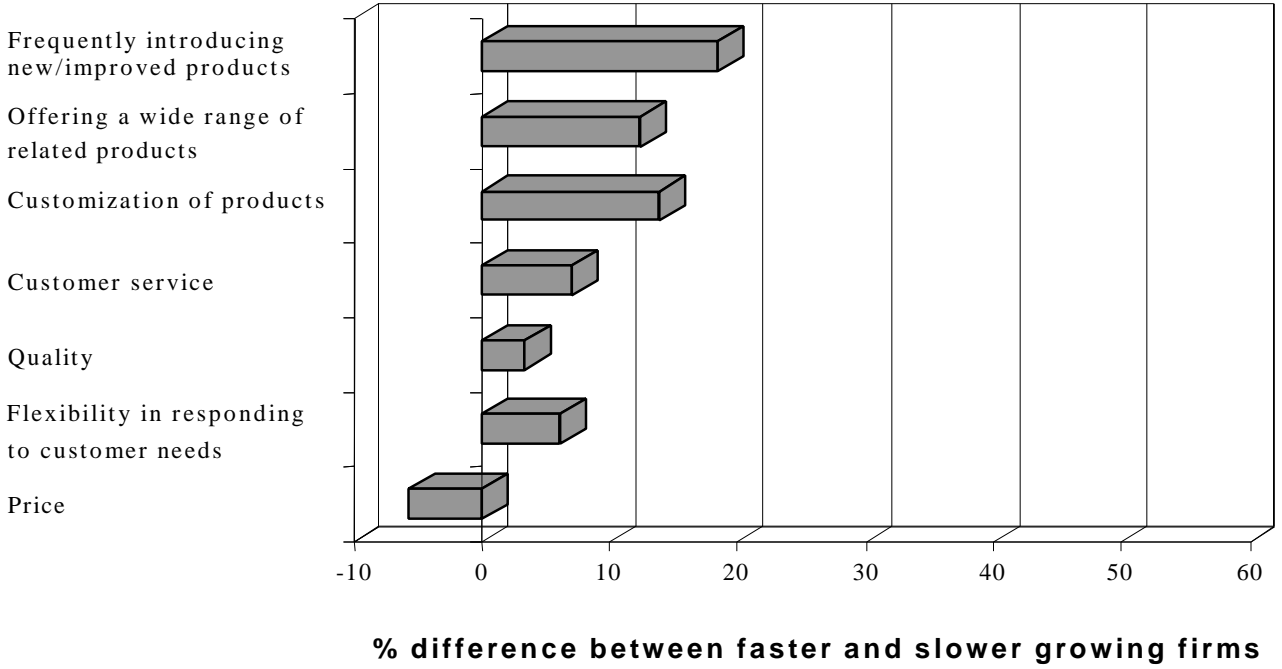

The emphasis on enhancing product lines or expanding market share does not come at the expense of improving production efficiencies. Faster growing entrants also rate each of the production-related strategies more highly than slower growing entrants (Figure 16).

The type of innovation activity that is associated with growth depends on the stage of the market in which the entrant is located. In new product markets that are in their early growth phase, the characteristics of the product are continually changing. In these volatile markets, the successful entrants that grow are those that keep pace with or lead product changes: growing entrants are those that emphasize product development strategies. Emphasis on improving the way existing products are produced, or extending their market reach, is less strongly related to growth. Successful entrants that grow in these markets are those that anticipate and stimulate demand for new product features, and focus on product development. At this stage of development, product change is so rapid that firms have little time to focus on improvements in the production process, and there is relatively less to gain by focusing on improving the efficiency with which existing products are produced.

The percentage difference in the scores for product strategies between faster and slower growing entrants in each of mature markets and new markets is presented in Figure 17. Growing entrants in new markets attribute significantly greater importance to frequently introducing new products and customizing products. 
Figure 15. Differences in the Importance of Marketing Strategies Between Faster and Slower Growing Entrants

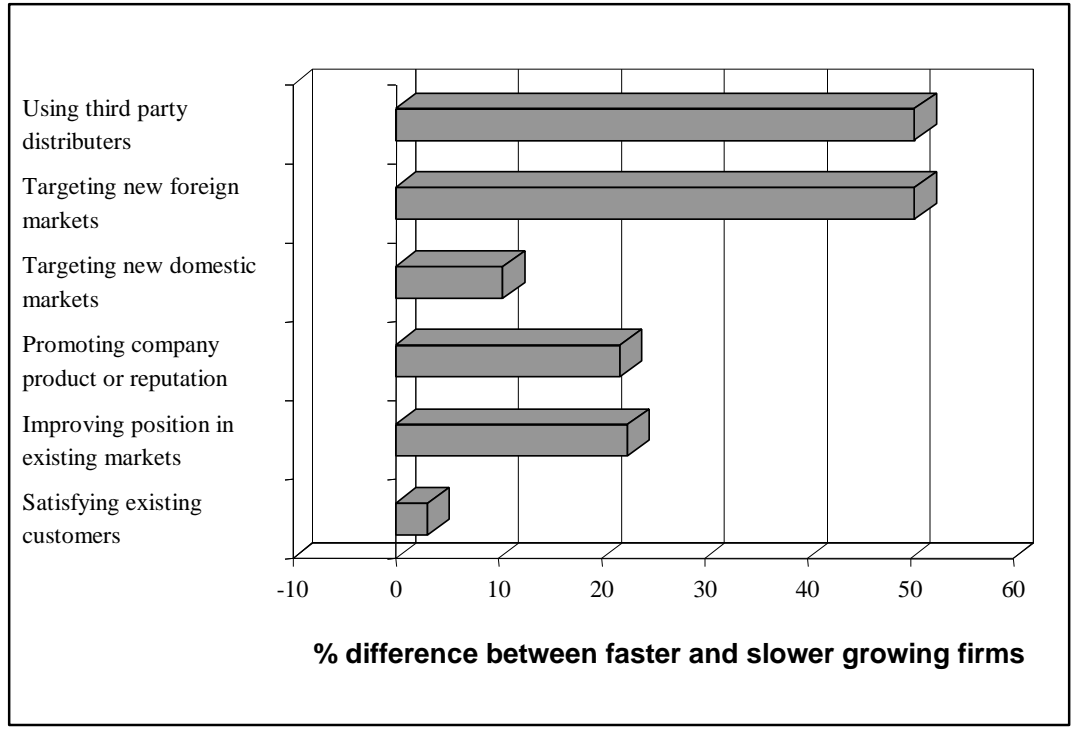

Conversely, firm growth in new markets is less associated with production related strategies (Figure 18). Attention to these production strategies is positively associated with firm growth in new markets, but not as strongly as attention to product strategies. Moreover, attention to production strategies is less strongly associated with firm growth in new markets than it is in mature markets.

Figure 16. Differences in the Importance of Production Strategies Between Faster and Slower Growing Entrants

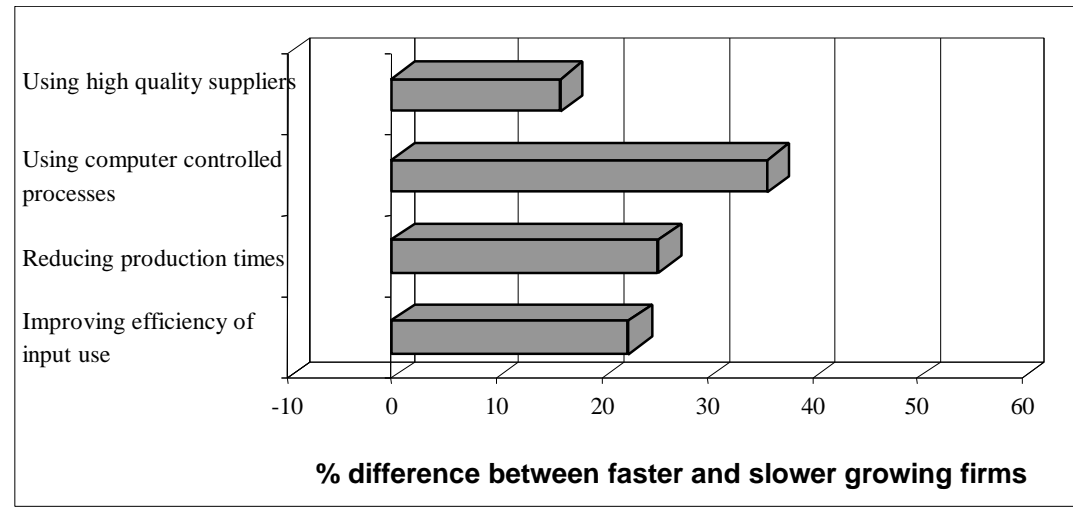


Figure 17. Differences in the Perceived Importance of Product Strategies Between Faster and Slower Growing Entrants

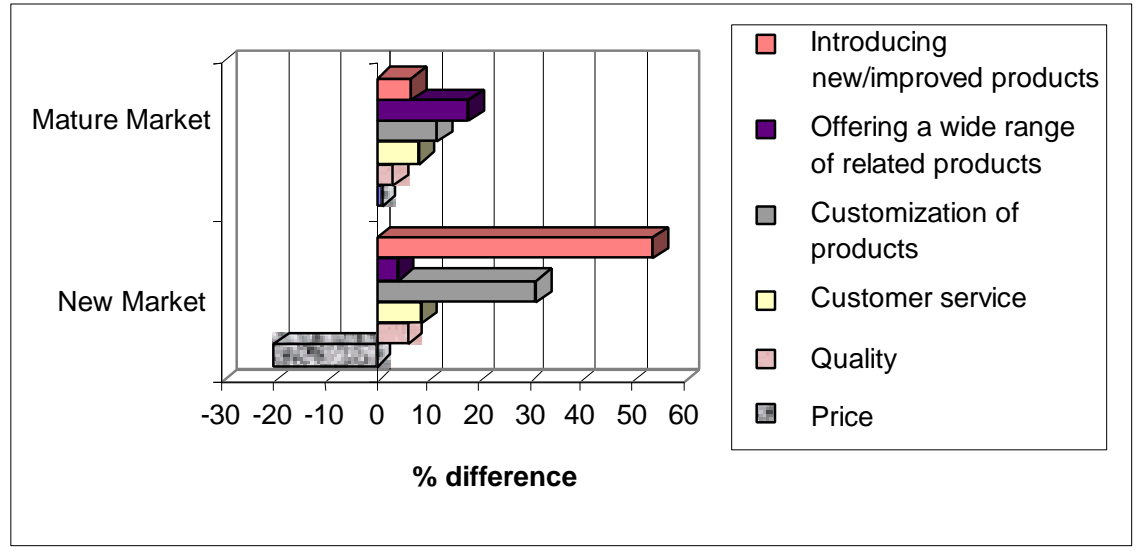

In contrast to new markets, the advantage in mature markets is related to the strategic emphasis on production and marketing. While there is less opportunity for the firm to gain a competitive advantage through product development in mature markets, some entrants do achieve rapid growth. Those that do so typically place greater emphasis on improving their production processes. Faster growing entrants attribute greater importance to 'using high quality suppliers', 'reducing production times' and 'improving the efficiency of input use'. Moreover, attention to these production strategies is more closely associated with growth in mature markets than is the case in new markets (Figure 18).

Market development is also strongly associated with growth in mature markets (Figure 19). While many Canadian markets are "mature", foreign countries frequently represent untapped potential opportunities for successful entrants. Indeed, strategic emphasis on foreign markets is strongly associated with growth in mature markets, but not in new markets.

Figure 18. Differences in the Perceived Importance of Production Strategies Between Faster and Slower Growing Entrants

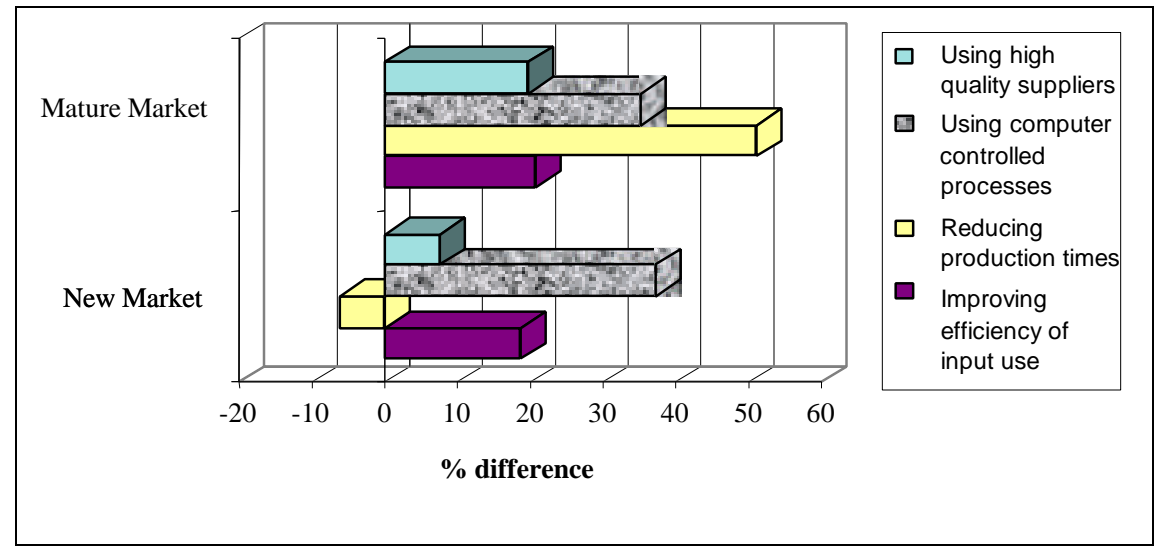


In summary, successful entrants are attentive to their established market. They are concerned about quality and customer service. The faster growing entrants are those that reach beyond the bounds of their established market. They introduce new and/or improved products, and seek out new customers. They look inside the firm and continually strive to improve, update and modify their operations. Despite the primary focus of entrants on established markets that has been drawn in the previous section, innovation in new firms is rewarded with growth. These results corroborate those found in the GSME survey (Baldwin et al., 1994) where faster growing firms outperform in every area, but where innovation is the key factor that discriminates between moreand less- successful firms.

Figure 19. Differences in the Perceived Importance of Marketing Strategies Between Faster and Slower Growing Entrants

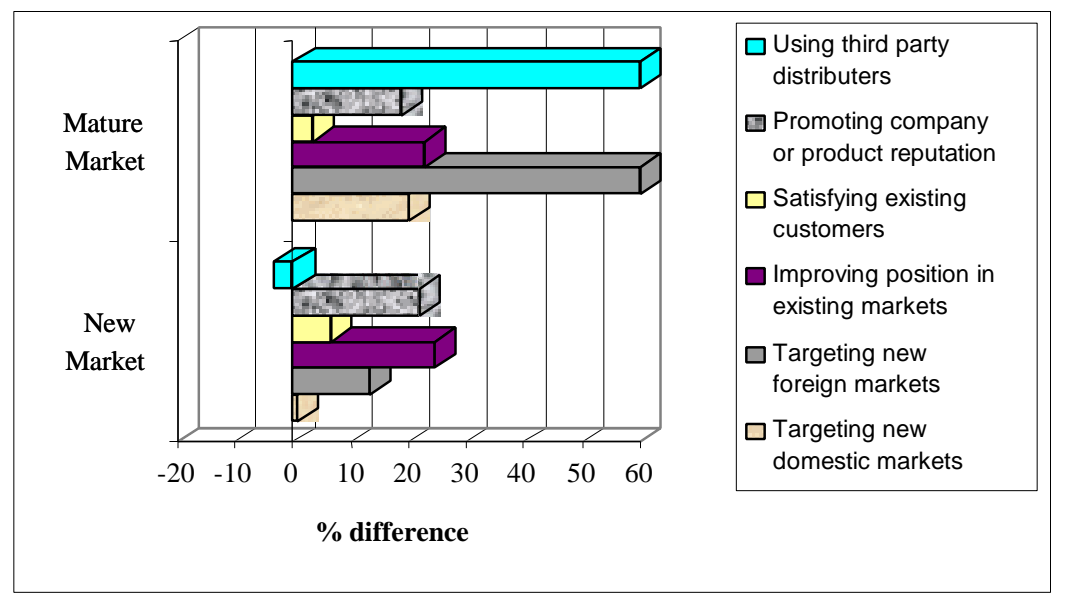

\subsection{Innovation and Complementary Competencies}

\section{How Do Innovators Differ From Non-innovators?}

This evidence indicates that the successful entrants that are innovative typically achieve stronger growth than those that do not innovate. Regardless of the industry in which the new firm operates or the maturity of the market that the firm serves, innovators grow faster than non-innovators.

It is important to understand how innovators differ from non-innovators. Such an analysis provides information on the competencies that appear to be complementary to innovation. The finding that certain characteristics or competencies are strongly associated with innovation suggests that entrants may not be able to innovate successfully without also developing those complementary competencies. For example, previous studies of small firms in general (Baldwin and Johnson, 1996b), find that innovative firms tend to train more, thereby suggesting that government policies that recognize the complementarities between innovation and training are going to be more productive than technology policies or human resource policies that are formulated without consideration being given to the complementarity between the two. 
Previous studies (Baldwin and Johnson 1996a) have found that more-innovative, established SMEs tend to demonstrate superior capabilities across the entire range of business competencies than less-innovative established SMEs. This is confirmed by the data contained in the survey of entrants. Innovators develop superior competencies in all areas, including management, technology, human resources, marketing, and production. They also counter the greater uncertainty that they face by undertaking more formalized planning and monitoring their performance. Finally, they have built a capital structure that affords more flexibility and reduces exposure to risk in financial markets, by drawing on more types and sources of financing.

To investigate the relationship between innovative activity and the emphasis given to different business strategies, the average score was calculated for all questions that measured specific competencies in a particular functional area. For example, the overall score in human resources consisted of the average score given to the importance of training, recruiting skilled employees, and providing incentive compensation plans; for financing, the average given to the importance of finding and maintaining capital, financial management of cash flow, and flexibility in meeting unforeseen circumstances; for technology, the importance given to developing new technology, purchasing advanced technology, and R\&D capabilities; for production, the importance given to improving the efficiency of inputs, reducing production times, using computer controlled processes, and using high quality suppliers; for marketing, the scores were derived from the importance given to targeting new domestic markets, new foreign markets, improving position in existing markets, promoting company reputation, and using third-party distributors. These averages were then compared for innovators and non-innovators.

Innovators place significantly more emphasis on almost all of the broad areas (Figure 20). Specifically, they place more emphasis on management, human resource, technology, marketing, and production strategies than non-innovators. The biggest difference lies in the valuation of technology strategies. The only area to which they do not give significantly greater emphasis is financing strategies; these strategies are valued highly by both innovators and non-innovators alike.

The stronger strategic emphasis in each of the areas is translated into action. Innovators are significantly more likely to train, export and incur investment expenditures (Figure 21). Specifically, they are significantly more likely to invest in R\&D, technology, market development, training, and machinery and equipment (not reported here).

With respect to their product strategies, innovators place more emphasis on customizing products, offering a wide range of products, and frequently introducing new/improved products than do non-innovators (not reported here). In the more traditional areas of price, quality, and customer service, innovators do not score significantly differently than non-innovators.

There is also a significant difference in the capital structure in innovative and non-innovative entrants. Innovators are significantly more likely to depend on multiple types and sources of capital (Table 2). This offers them greater flexibility and protection from financial risk. Hence, innovators are better able to enjoy the benefits that different types of capital afford, but to accomplish this they have to diversify their sources of funds. 
The importance given to managing the business, in the face of intense competition and uncertainty is manifested by a greater emphasis on business planning and monitoring behaviour. Innovators are almost twice as likely to have a business plan, and more than twice as likely to have a financial plan.

In summary, it is apparent that innovators face a more competitive environment and greater uncertainty than do non-innovators in a number of innovation-related areas. Their superior business competencies, as demonstrated both by their pursuit of various business strategies, and the undertaking of investment, training and exporting, suggest that they develop a superior set of competencies to adapt to this environment.

\section{Figure 20}

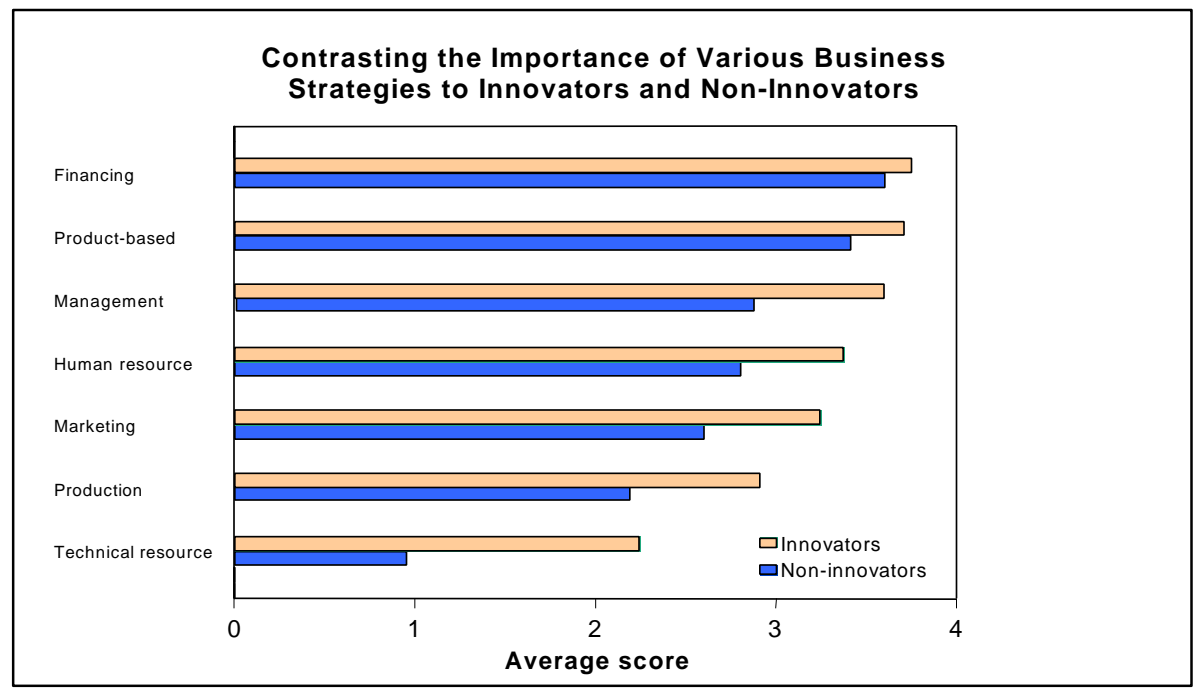

Table 2. Percentage of Entrants Relying on Various Types of Financing

\begin{tabular}{|l|c|c|}
\hline \multicolumn{1}{|c|}{ Type } & Non-innovators & \multicolumn{2}{c|}{ Innovators } \\
\cline { 2 - 3 } & \multicolumn{2}{|c|}{ \% of entrants } \\
\hline Entrants relying on a single type of financing & $\mathbf{5 2}$ & $\mathbf{3 8}$ \\
Permanent capital & 26 & 27 \\
Semi-permanent capital & 11 & 6 \\
Non-permanent capital & 15 & 6 \\
Entrants relying on multiple types of financing & $\mathbf{4 8}$ & 5 \\
Permanent and semi-permanent capital & 10 & 23 \\
Permanent and non-permanent capital & 15 & 30 \\
Permanent, semi- and non-permanent & 19 & 4 \\
Semi- and non-permanent capital & 4 & $\mathbf{6 2}$ \\
\hline
\end{tabular}

Note: numbers may not add due to rounding. 
Figure 21

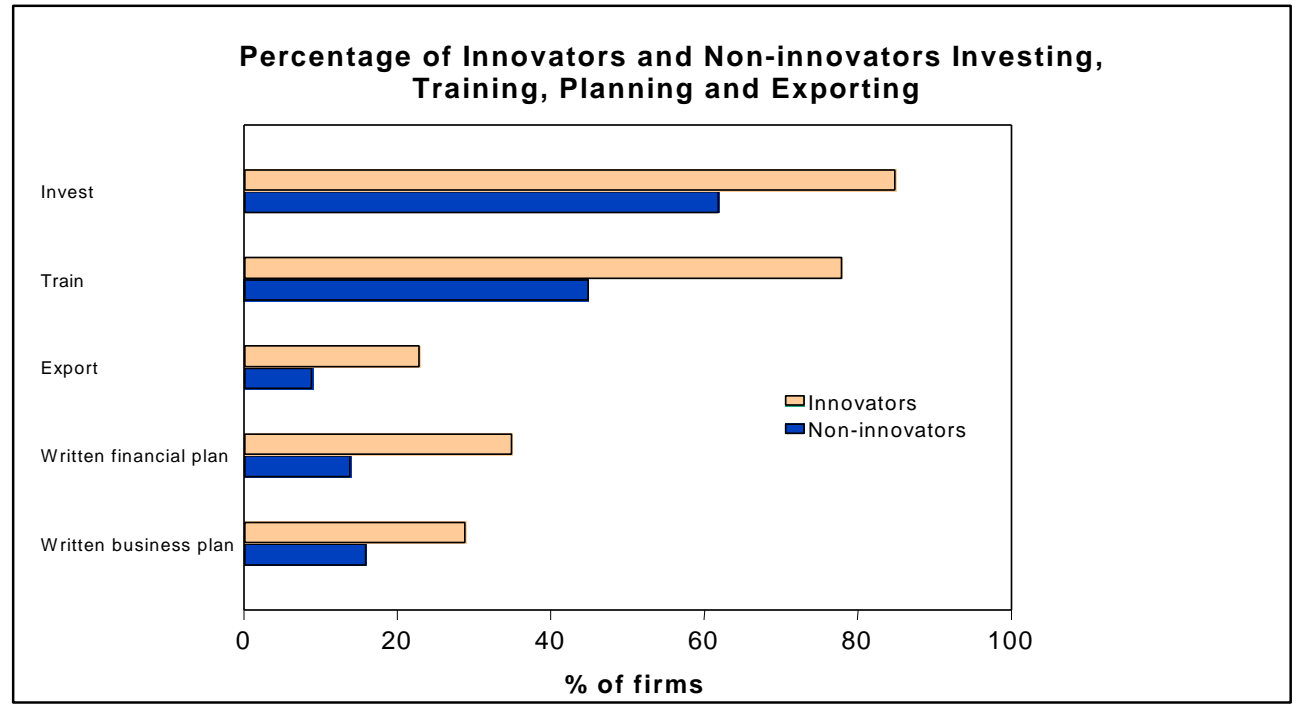

\section{Exit: A Profile}

Exit is a concomitant part of the entry process. A substantial proportion of exits comes from recent entrants. Why do so many entrants fail? Is it just the luck of the draw or are there some areas where resolvable problems have caused failure?

One explanation for the causes of exit is that it is the process that winnows out the most inefficient entrants. Evidence on the dispersion of wages, or size, or labour productivity indicates that new firms differ substantially in terms of their efficiency (Baldwin, 1995). While potential entrepreneurs can to some extent assess their capabilities and their chances of success prior to their actually starting a business, the ultimate test of their potential requires that they gamble on their abilities and create a new firm. It is only after that act of creation that the market will reveal whether their expectations were correct.

Most failures of entrants shortly after birth result from new entrepreneurs making incorrect assessments of their capabilities. Exit is not a random phenomenon. Previous studies have shown that exiting firms tend to be systematically different from those who survive. Baldwin and Rafiquzzaman (1996) demonstrate that entrants who do not survive are smaller, pay lower wages and have lower productivity. Indeed, cohorts of entrants who start off paying lower wages as a group than incumbent firms gradually catch up to the incumbent population because the most inefficient among them fall by the wayside.

Size, productivity, and financial structure of entrants are all manifestations of underlying managerial strategies and competencies. In order to comprehend the causes of failures, an understanding of the underpinnings of new firms is required. New firms do not succeed or fail because they pick a certain size, or a certain wage rate. Both size and wage rates result from 
whether the firm offers a product that consumers value. That in turn depends on the capabilities of the entrepreneur in a wide range of different areas-general management, production, human resources, marketing, and finance. The previous section reported on the characteristics of those entrants who survive infancy. This section describes the failings of those who exit.

A detailed analysis of the factors associated with exit can be drawn from a survey of a group of Canadian businesses that fail-corporate bankruptcies. While basic statistics on the extent and trends in exit can paint a picture of the magnitude of the process, they do not explain why firms go bankrupt. It is important to ask why, of a set of firms facing similar market conditions, will some survive and others fail? Is it a product of the environment and, therefore, not easily controlled? Or, is it the result of internal failure on the part of management? Are the problems that arise within firms rectifiable? If so, what can these firms do to avoid bankruptcy? To understand these problems, a richer set of data is required than is provided by longitudinal databases on numbers of exits by industry. Information on the basic competencies of exiting firms is required. This section summarizes the findings of a recent survey that develops just such a database.

\subsection{The Survey of Bankrupts}

The Survey of the Characteristics of Bankrupt Firms (Baldwin et al., 1997) presents a detailed picture of corporate failures in Canada. The survey uses a taxonomy based on the functional areas that must be mastered by a successful firm - management, financing, human resources, marketing, and production - to organize information on the causes of bankruptcy. While grounded in the bankruptcy literature, the survey also builds on the extensive organizational and entrepreneurial theories of firm failure, making use of both quantitative (such as revenue and number of employees) and qualitative (such as management ability and financial expertise) data. As well, it draws from other studies of the competencies contained in small firms (Baldwin et al., 1994) that examine the factors that contribute to a firm's success. This literature finds that several key controllable competencies must be present, at least to some degree, for firm survival and growth, which in turn suggests that a lack of several of these key capabilities, in combination with environmental and contextual factors, may result in firm failure.

The survey questionnaire focused its attention on four areas: the characteristics of bankrupt firms, the external (uncontrollable) factors that cause failure, the internal (controllable) factors that cause failure, and the onset and prevention of bankruptcy.

Information on the general characteristics of bankrupt firms-age, size, governance structure, business experience of the manager, industry, geographic location-provide a picture of a typical bankrupt firm in Canada.

While information on the characteristics of bankrupt firms is important, it alone does not identify the external and internal factors that caused exit. External factors include economic downturn, unforeseen circumstances (such as natural disaster or adverse publicity), theft or fraud, increased competition, legislation and government regulations, supplier or customer difficulties, and fundamental changes in technology or market conditions beyond the control of the firm. Internal 
causes of bankruptcy arise from possible deficiencies in: general management skills, firm strategies, expansions and buyouts, financial planning, financial management and record keeping, human resources, marketing, and production and operations.

The general management skills that are examined include deficiencies in knowledge, abilities, attitudes, and actions, breadth and depth of knowledge and vision, poor supervision of staff, and lack of emphasis on product quality. Specific management failure with regard to planning is also examined. Other firm strategies that are investigated include the use of outside advisors, and the emphasis placed on strategic goals, such market expansion, buyouts, and profitability. Finally deficiencies with regard to financial management and record keeping were investigated.

Bankruptcy can also be associated with weaknesses in the human resources policies followed by a firm. Firms that are not able to attract skilled labour, whether it is because they do not offer the going wage rates for skilled workers or because of a lack of skilled workers in their geographic area, are more likely to fail. Since many bankrupt firms are small and rely on a few key people, personal problems of management can also contribute to bankruptcy.

Deficiencies in the area of marketing can directly lead to inadequate sales and act as a significant cause of bankruptcy. Marketing strategies attract customers. Examples of inadequate marketing strategies that were investigated include poor location, inferior products, and poor customer service.

The survey not only investigates the extent to which specific problems within each internal category-management, finance, human resources, production, and marketing-were a prime cause of bankruptcy, it also examines which of these areas ranks as the most important. Was it the foundation on which a firm rests-its management structure? Or, was it a failure in one of its subcomponents-such as technology strategy? It then examines whether these internal factors taken as a whole were more or less important than external factors that are outside the control of the firm. In doing so, it examines whether the downfall of the firm originated in events outside the control of the firm. It then asks whether bankruptcy in these circumstances (an external shock) was accompanied by particular internal problems. Did the lack of certain basic skills make the firm more vulnerable to a shock in its external environment?

A firm's access to credit and the cost of credit are generally seen to be critical to new young firms. Lending institutions have identified a lack of proper business and financial management skills in potential clients as one cause of insufficient access to financial capital. Others argue that the problem may just as well be related to institutional rigidities that inappropriately deny some firms access to credit. Therefore, the survey investigated whether access to credit was a particular problem for the bankrupt firm. The survey separates the issue of access to credit into internal factors (such as financial or managerial incompetence) and external factors (such as policies of financial institutions).

\subsection{Findings}


The study found that bankrupt firms are generally quite young-63.1\% of bankrupt firms failed within the first five years of starting operations. The majority $(30.5 \%)$ of the remaining groups of bankrupt firms were less than 15 years old. Failure is also predominantly a small-firm phenomenon.

Management and industry experience are critical for the learning process. While only $46 \%$ of managers had worked more than four years for the bankrupt firm, this is partly due to the young age of most bankrupt firms. Managers actually had more experience in the industry. Some $73 \%$ had more than four years experience in the industry; some $66 \%$ had more than four years experience as a manager. Nevertheless, the younger bankrupts had managers that had considerably less experience than managers in older firms. Age of the firm and experience of the manager are closely related.

Many firms in Canada go bankrupt because of events that are partially beyond their control. There is a certain random stochastic process at work. These include such events as economic downturn in the market facing the firm, increases in competition, loss of a major customer as the result of relocation or market change, government regulation, technological change, employee fraud, or labour legislation. Some $68 \%$ have been affected to some degree by an economic downturn in their market. In addition, increases in competition and customer difficulties (such as the loss of key customers or volatile demand) are also significant factors behind firm failure.

While factors beyond a firm's control play a role in failure, even when external factors are assessed as having some importance, internal failings are still found to exist. Almost half of the firms in Canada that go bankrupt do so primarily because of their own deficiencies rather than just because of externally generated problems. Internal causes of bankruptcy include problems associated with general management skills, firm strategies, expansions and buyouts, financial planning, financial management and record keeping, human resources, marketing, and production and operations.

Firm failure that occurs as a result of internal problems is primarily rooted in the deficiencies of a firm's management. Managers of bankrupt firms do not have the experience, knowledge, or vision to run their businesses. Even as firms age and management experience increases, knowledge and vision remain critical deficiencies that contribute to failure.

A second key deficiency in bankrupts occurs in the area of financial management. Some $71 \%$ of firms that fail are characterized by poor financial planning. Three particular problems that arise in this area are an unbalanced capital structure, an inability to manage working capital, and undercapitalization. Both old and young bankrupt firms suffer this deficiency.

Firms that go bankrupt in Canada also lack the basics in marketing capabilities. Marketing strategies attract clients and a firm cannot succeed without customers. The problems that bankrupt firms face in this area are substantial - they fail to establish a market niche and often fail to locate in a suitable location.

Even when it comes to financial difficulties, it is management failure rather than external factors associated with imperfect capital markets that matter most. Often institutional barriers to capital 
do present a major problem to these firms. However, these barriers are almost always associated with internal management deficiencies. In particular, a large percentage of firms that face an external capital constraint also lack the knowledge to pursue different financing options. Moreover, imperfections in capital markets feed on themselves. A firm that cannot raise equity capital faces more barriers from financial institutions.

The management of new firms face a learning curve. In the early stages of life, internal deficiencies are so prevalent that most bankruptcies occur for these reasons. Management must master the basic internal skills-general and financial knowledge, control, communications, supervision of staff, and market development—or it will fail solely or primarily from the weight of these problems. As a surviving business grows, a new set of problems arises that are associated with the increased complexity of running an older and often larger firm. Managerial issues such as the poor use of outside advisors, lack of emphasis on quality, an unwillingness to delegate responsibilities, departure of key personnel, and personal problems associated with the owner/manager become relatively more important factors contributing to failure as a firm ages.

Over half of bankrupt firms did develop these strengths, at least to the point that they did not fail primarily due to a lack of them. External events were cited as the primary cause of their downfall. But even here, these firms still suffer from deficiencies that are partly of their own doing. They did not develop the internal competencies necessary to ride through the external shock, such as an economic downturn or increased competition, that caused bankruptcy. While poor management skills were generally less of a factor in firms that failed for external reasons, managers' deficiencies such as lack of vision, initiative, flexibility, and adaptability were still problems that were associated with bankruptcy. Marketing competencies were also relatively more important in the case of externally generated failures than for internally related failures.

In summary, the rich information provided by the survey shows that bankrupt firms in Canada lack the basic competencies to survive. It confirms the earlier work that, on the basis of simple characteristics like wages paid and labour productivity, concluded that entrants who fail are basically inferior to those that succeed. The evidence from the bankruptcy survey indicates bankruptcies are not caused by deficiencies in sophisticated management; they result from a new firm's inability to master the basics. 


\section{Conclusion}

Entry is important. It is an inherent part of the dynamic competitive process that leads some firms to grow and others to decline. And it is within this context that it needs to be appreciated. It is not the only process at work-but it is an important part of it.

There is a tendency to understate the role of entry for several reasons. First, it is primarily a small firm phenomenon and as such can all too easily be described as an event relevant only to the fringe in an industry. It is also difficult to measure, especially its cumulative effect. Second, there are a large number of failures in every class of entrants. The process by which many firms enter an industry and few survive is inherently untidy. It has been likened to a churning process-where a large amount of milk has to be worked in order to produce a small quantity of butter. Moreover few of each class or group of entrants become large and the growth that does occur is generally slow. In a world where the focus is on gazelles that manage growth rates of over $100 \%$ every five years, the progress of most entrants is painfully slow. Moreover, the notion that scientific research and development laboratories are critical to economic growth and its association mainly with large firms has influenced the way in which many think about the contribution made by small firms to innovation.

We have argued here that the entry process is indeed important for several reasons. First, a careful examination of the data on the rates of entry shows that entry becomes important when the effects of successive classes of entrants are accumulated. At any point in time, a substantial amount of market share or employment is accounted for firms in the recent past—not a gargantuan amount, but an amount that cannot be dismissed as marginal.

The process at work does involve trial and error. Firms have to develop basic skills before they can survive-and large numbers appear not to have these skills at birth. Firms that fall by the wayside generally start off smaller, pay lower wages and have lower labour productivity. Moreover, their management lacks knowledge of basic management skills in many cases. Nevertheless, there is a subset of new entrants that survive and grow-and the growth of this group is substantial.

The effect of entry does not have to be measured just by the market share for which it accounts. Entry affects the productivity growth in an industry and its innovative capabilities. Entry affects productivity growth primarily by being the force that drives productivity growth in the small-firm part of the firm-size distribution. Entrants drive out firms that cannot keep up. When viewed in this way, entrants provide about the same contribution to productivity growth as they account for the share of output.

It is in the area of innovation that entrants make a widespread contribution. The contribution of entrants to some industries is well understood. New technology-based firms play an important role in the early stages of the life-cycle of many industries. They are the means by which the ideas of new entrepreneurs are initially commercialized. Whether it be in electronics, instruments, medical equipment, steel, or biotechnology, new firms have played an important role in the innovation process. 
Despite the high profile of entrants in industries such as electronics and biotechnology, the role of small firms is still questioned. As important as these high profile firms are, generalizing their impact to other sectors is difficult based just on case studies. And it is all too easy to infer that firms in other sectors are not innovative. There is a tendency to apply emotive terminology like the knowledge economy to the high profile sectors, thereby implying that small firms elsewhere are low-tech or low-knowledge. This paper argues that this is inappropriate. While there is no doubt that firms in the electronics industries are innovative, it is also the case that firms elsewhere have developed the capacities that are needed for innovation in their particular industries. These capabilities often involve developing new technology, or nurturing of worker skills, or devising new products that are highly novel. The range and diversity of the innovative skills of new firms across all industries is remarkable.

Our results show that small firms in general and entrants in particular are heterogeneous. Some resemble larger firms in that their innovation system is based on R\&D. However, the lack of R\&D facilities does not imply that a small firm is non-innovative. Many entrants develop new products without a formal R\&D system, either because they rely on other internal sources such as marketing or production, or because they are part of an innovation network with suppliers and customers.

In conclusion, the debate over whether small firms are more innovative than large firms has been shaped by data and semantic difficulties. In the first instance, lack of data on innovation led to R\&D becoming the main focus of discussion-which because of inherent differences in the innovative process in many small firms biased the findings against this group. When empirical work then turned to measuring outputs of the innovation process rather than inputs, semantic difficulties severely restricted the debate. In an attempt to define innovation in a single manner with a simple phrase, the variety of strategies that were pursued by new firms was lost. In doing so, a straitjacket was placed on the definition of innovation that caused the debate to focus on the wrong issue-whether small firms look like large firms. In reality, small firms are not simply miniature versions of large firms. They often serve a different stage of the product life-cycle. They generally exist in different industries. They serve different markets. Their production process is not the same. All this leads to a different but multifaceted innovation process.

The importance of the innovation process is attested to by the connection between growth and innovation. The successful entrants that grow the most are those that develop one or other type of innovative activity-either with respect to the introduction of new products, an emphasis on technology or human resources.

We have also shown that this innovation process, to be successful, requires complementary skills. Firms that develop new products have to focus more intensely on human resource capabilities. They develop access to more sources of financing. They develop competencies in a number of different areas. For example, innovation activities are accompanied by a greater emphasis on accompanying skills. This requires balance. An innovative firm focuses more intensely on a range of competencies. 
Finally, we have shown that the small, new firms that fail differ substantially from those succeeding. Previous work (Baldwin and Rafiquzzaman, 1996) had focussed on differences in a limited range of variables_-such as size, productivity, and the wage rate. This study extends this comparison to the nature of the competencies developed across a wide range of functional areas. These are the same competencies that are examined for surviving entrants. The differences that are found between surviving entrants and bankrupts resemble differences found between the faster and slower growing survivors. ${ }^{29}$ Thus, we find that the factors that differentiate faster from slower growing survivors are much the same factors that distinguish survivors from failures.

${ }^{29}$ This provides evidence that the differences associated with growth in the surviving population are not the result of selection bias. 


\section{References}

Abernathy, W.J. and J.M. Utterbach. 1978. "Patterns of Industrial Innovation," Technology Review June/July 80: 41-7.

Acs, Z.J. and D. Audretsch. 1987. "Innovation, Market Structure and Firm Size, "Review of Economics and Statistics 69: 567-75.

Acs Z.S. and D.B. Audretsch. 1990. Innovation and Small Firms. Cambridge MA: MIT Press.

Acs, Z.J. and D. Audretsch (eds.) 1991. Innovation and Technological Change. Harvester: Wheatsheaf.

Agarwal, R. and M. Gort. 1996. "The Evolution of Markets and Entry, Exit and the Survival of Firms," Review of Economics and Statistics 78(3): 489-98.

Audretsch, D.B. 1995. Innovation and Industry Evolution. The MIT Press.

Aw, B.Y, X. Chen and M.J. Roberts. 1997. "Firm-level Evidence on Productivity Differentials, Turnover, and Exports in Taiwanese Manufacturing", in D.B. Audretsch and R.A. Thurik (eds.), Innovation, Industry Evolution and Employment. Cambridge University Press.

Bailey, M.N., C. Hulten and D. Campbell. 1992. "Productivity Dynamics in Manufacturing Plants," Brookings Papers on Economic Activity: MicroEconomics 1992. 187-267.

Baldwin, J.R. 1995. The Dynamics of Industrial Competition. Cambridge University Press.

Baldwin, J.R. 1996. "Productivity Growth, Plant Turnover and Restructuring in the Canadian Manufacturing Sector," in D. Mayes (ed.) Sources of Productivity Growth, Cambridge University Press.

Baldwin, J.R. 1997. The Importance of Research and Development for Innovation in Small and Large Canadian Manufacturing Firms. Research Paper No. 107. Analytical Studies Branch. Ottawa: Statistics Canada.

Baldwin, J.R. and G. Gellatly. 1998. Are there High-Tech Industries or only High-Tech Firms? Evidence from New Technology-Based Firms. Research Paper No. 120. Analytical Studies Branch. Ottawa: Statistics Canada.

Baldwin, J.R., W. Chandler, C. Le and T. Papailiadis. 1994. Strategies for Success: A Profile of Small and Medium-Sized Enterprises in Canada. Catalogue No. 61-523RE. Ottawa: Statistics Canada. 
Baldwin, J.R. and M. Da Pont. 1996. Innovation in Canadian Manufacturing Enterprises. Catalogue No. 88-513-XPB. Ottawa: Statistics Canada.

Baldwin, J.R., T. Dunne and J. Haltiwanger. 1998. "A Comparison of Job Creation and Job Destruction in Canada and the United States," Review of Economics and Statistics 80: 347-57.

Baldwin, J.R., R. Dupuy and W. Penner. 1992. "Development of longitudinal panel data for business registers: Canadian experience," Statistical Journal of the United Nations Economic Commission for Europe 9: 289-303.

Baldwin, J.R. and P.K. Gorecki. 1990. Structural Change and the Adjustment Process: Perspective on Firm Growth and Worker Turnover. Economic Council of Canada and Statistics Canada. Ottawa: Minister of Supply and Services.

Baldwin, J.R. and P.K. Gorecki. 1991. "Productivity Growth and the Competitive Process: the role of firm and plant turnover," in Geroski, P.A. and Schwalbach, J. (eds.) Entry and Market Contestability: An International Comparison. Oxford: Basil Blackwell.

Baldwin, J.R., T. Gray and J. Johnson. 1996. "Advanced Technology Use and Training in Canadian Manufacturing," Canadian Business Economics 5(1): 51-70.

Baldwin, J.R., T. Gray, J. Johnson, J. Proctor, M. Rafiquzzaman and D. Sabourin. 1997. Failing Concerns: Business Bankruptcy in Canada. Catalogue No. 61-525-XPE. Ottawa: Statistics Canada.

Baldwin, J.R. and J. Johnson. 1996a. "Human Capital Development and Innovation: A Sectoral Analysis," in Peter Howitt (ed.) The Implications of Knowledge-Based Growth for MicroEconomic Policies. Calgary: Calgary University Press.

Baldwin, J.R. and J. Johnson. 1996b. "Business Strategies in More- and Less-innovative Firms in Canada", Research Policy 25: 785-804.

Baldwin, J.R. and M. Rafiquzzaman. 1996. "Selection versus Evolutionary Learning: Learning and Post-entry Performance," International Journal of Industrial Organization 13: 501-22.

Baldwin, J.R. and D. Sabourin. 1996. Technology Adoption in Canadian Manufacturing. Catalogue No. 88-512-XPB. Ottawa: Statistics Canada.

Cable, J. and J. Schwalbach. 1991. "International Comparisons of Entry and Exit, " in P.A. Geroski and J. Schwalbach (eds.) Entry and Market Contestability: An International Comparison. Oxford: Basil Blackwell.

Chakrabati, A.K. and M. R. Halperin. 1990. "Technical Performance and Firm Size: Analysis of Patents and Publications of U.S. Firms," Small Business Economics 2(3): 183-90. 
Cohen, W.M. and D.A. Levinthal. 1989. "Innovation and Learning: The Two Faces of R\&D," Economic Journal 99: 569-96.

Cohen, W.M. and R.C. Levin. 1989. "Empirical Studies of Innovation and Market Structure," in R. Schmallensee and R. Willig (eds.) Handbook of Industrial Organization. Volume II. Amsterdam: North-Holland. 1059-1107.

Cohen, W.M. and S. Klepper. 1992. "The Tradeoff Between Firm Size and Diversity in the Pursuit of Technological Progress," Small Business Economics 4: 1-14.

Cohen, W.M. and S. Klepper. 1996a. "A Reprise of Size and R\&D”, Economic Journal 106: 915-52.

Cohen, W.M. and S. Klepper. 1996b. "Firm Size and the Nature of Innovation within Industries: The Case of Process and Product R\&D," Review of Economics and Statistics 78:22-43.

D’Amboise, G. 1991. The Canadian Small and Medium-Sized Enterprise: Situations and Challenges. Halifax: The Institute for Research on Public Policy.

Davies, S. 1979. The Diffusion of Process Innovations. Cambridge: Cambridge University Press.

Davis, S.J., J. Haltiwanger and S. Schuh. 1996. Job Creation and Destruction. MIT Press.

Dunne, T., M. Roberts and L. Samuelson. 1988. "Patterns of Firm Entry and Exit in U.S. Manufacturing Industries," Rand Journal of Economics 19(4) 495-515.

Enos, J.L. 1962. Petroleum Progress and Profits: A History of Process Innovation. MIT Press.

Fleissner, P., W. Hofkirchner and M. Pohl. 1993. “ The Austrian Experience with Literature-based Innovation Output Indicators," in A.H. Kleinknecht and D. Bain (eds.) 1993. New Concepts in Innovation Output. London: Macmillan.

Freeman, C. 1971. The Role of Small Firms in Innovation in the United Kingdom since 1945. Research Report No. 1 Committee of Inquiry on Small Firms. London: Her Majesty's Stationery Office.

Freeman, C. 1982. The Economics of Industrial Innovation. Cambridge, Mass: MIT Press.

Geroski. P.A. 1991. Market Dynamics and Entry. Basil Blackwell.

Geroski, P.A. and J. Schwalbach. 1991. Entry and Market Contestability: An International Comparison. Oxford: Basil Blackwell.

Griliches, Z. and H. Regev. 1995. "Firm Productivity in Israeli Industry, 1979-1988". Journal of Econometrics 65: 175-203. 
Gort, M. and S. Klepper. 1982. "Time Paths in the Diffusion of Product Innovations," Economic Journal 92:630-53.

Haltiwanger, J. 1998. "Measuring and Analyzing Aggregate Fluctuations: The Importance of Building from Micro-Economic Evidence," St. Louis Fed. Reserve Bank Econ. Rev.

Hamberg, D. 1963. "Invention in the Industrial Research Laboratory," Journal of Political Economy 71: 95-115.

Hazledine, T. 1985. "The Anatomy of Productivity Growth Slowdown and Recovery in Canadian Manufacturing," International Journal of Industrial Organization 3: 307-26.

Hollander, S. 1965. The Sources of Increased Efficiency: A Study of Dupont Rayon Plants. MIT Press.

Jewkes, J., D. Sawers and R. Stillerman. 1959. The Sources of Invention. London. MacMillan.

Kirzner, I. 1972. Competition and Entrepreneurship. Chicago: University of Chicago Press.

Kleinknecht, A. 1987. “Measuring R\&D in Small Firms: How Much are We Missing?" Journal of Industrial Economics 36(2): 253-56.

Kleinknecht, A. 1989. "Firm Size and Innovation: Observations in Dutch Manufacturing Industry," Small Business Economics 1(1) 215-22.

Kleinknecht, A., T.P. Poot and J.O.N. Reijnen. 1991. "Technical Performance and Firm Size: Survey Results from the Netherlands," in Zoltan J. Acs and David B. Audretsch (eds.) Innovation and Technological Change: An International Comparison. Ann Arbor: University of Michigan Press.

Kleinknecht, A.H., J.O.N. Reijnen and W. Smits. 1992. "Collecting Literature-based Innovation Output Indicators. The Experience in the Netherlands," in A.H. Kleinknecht and D. Bain (eds.) 1993. New Concepts in Innovation Output. London: Macmillan.

Kleinman, H.S. 1975. Indicators of the Output of New Technological Products from Industry. Report to US National Science Foundation, National Technical Information Service, US Department of Commerce.

Klepper, S. 1996. "Entry, Exit, Growth and Innovation over the Product Life Cycle," American Economic Review 86: 562-83.

Klepper, S. and J.H. Millar. 1995. "Entry, Exit and Shakeouts in the Unites States in New Manufactured Products," International Journal of Industrial Organization 13(4): 5678-91.

Knight, F.H. 1921. Risk, Uncertainty and Profit. New York: Harper. 
Link, A.N. and B. Bozeman. 1991. "Innovative Behavior in Small-Sized Firms," Small Business Economics 3: 179-84.

Link, A.N. and J. Rees. 1990. "Firm Size, University Based Research, and the Returns to R\&D”, Small Business Economics 2: 25-32.

Liu, Lili. 1993. "Entry-exit, Learning and Productivity Change: Evidence from Chile," Journal of Development Economics, 42: 217-242.

Liu, Lili and J.R. Tybout. 1996. "Productivity Growth in Chile and Colombia: The Role of Entry, Exit and Learning," in Industrial Evolution in Developing Countries, edited by M. Roberts and J. R. Tybout. Oxford University Press.

Mansfield, E. 1962. 'Entry, Gibrat's Law, Innovation and the Growth of Firms," American Economic Review 52: 1023-51.

Mansfield, E. 1968. Industrial Research and Technological Innovation. New York: Norton.

Mansfield, E. 1977. The Production and Application of New Industrial Technology. New York: Norton.

Mowery, D.C. and N. Rosenberg. 1989. Technology and the Pursuit of Economic Growth. Cambridge: Cambridge University Press.

Nabseth, L. and G.F. Ray (eds.). 1974. The Diffusion of New Industrial Processes: An International Study. London: Cambridge University Press.

Nelson, R.R. 1987. Understanding Technical Change as an Evolutionary Process. Amsterdam: North Holland.

Neuman, H. 1978. "Strategic Groups and Structure-Performance Relationship," Review of Economics and Statistics 60: 417-27.

OECD. 1996. Job Creation and Loss: Analysis, Policy and Data Development. Paris.

Olley, G.S. and A. Pakes. 1996. "The Dynamics of Productivity in the Telecommunications Equipment Industry," Econometrica.

Oster, S. 1982. "The Diffusion of Innovation Among Steel Firms: The Basic Oxygen Process," Bell Journal of Economics 13: 45-56.

Pakes, A. and R. Erickson. 1988. "Empirical Implications of Alternative Models of Firm Dynamics" A paper given to a conference entitled "Dynamic Aspects of Firm and Industry Behaviour". Cambridge, Mass: National Bureau of Economic Research. 
Peck, M.J. 1962. Competition in the Aluminium Industry: 1945-58. Cambridge, Mass: Harvard University Press.

Picot, G., J.R. Baldwin and R. Dupuy. 1994. Have Small Firms Created a Disproportionate Share of New Jobs in Canada? A Reassessment of the Facts. Research Paper No. 71. Analytical Studies Branch. Ottawa: Statistics Canada.

Rothwell, R. 1989. "Small Firms, Innovation and Industrial Change”, Small Business Economics 1: 5164.

Rothwell, R. and W. Zegveld. 1982. Innovation and the Small and Medium-Sized Firm. Frances Pinter: London.

Santarelli, E. and A. Sterlachinni. 1990. "Innovation, Formal vs. Informal R\&D, and Firm Size: Some Evidence from Italian Manufacturing Firms,” Small Business Economics 2: 223-28.

Scherer, F.M. 1992. "Schumpeter and Plausible Capitalism," Journal of Economic Literature. 30: 1416-34.

Schmookler, J. 1959. "Bigness, Fewness, and Research,” Journal of Political Economy 67: 628-32.

Schumpeter, J.A.1939. Business Cycles: A Theoretical, Historical and Statistical Analysis of the Capitalist Process. New York: McGraw-Hill.

Schumpeter, J.A.1942. Capitalism, Socialism, and Democracy. New York: Harper.

Shimsoni, D. 1970. “The Mobile Scientist in the American Instrument Industry," Minerva 3.

Soete, L.G. 1979. "Firm Size and Inventive Activity: The Evidence Reconsidered," European Economic Review 12: 319-40. 